\title{
Wear of CoCrMo alloys used in metal-on-metal hip joints: A tribocorrosion appraisal
}

\author{
Stefano Mischler ${ }^{\mathrm{a}, *}$, Anna Igual Muñoz ${ }^{\mathrm{b}}$ \\ a Ecole Polytechnique Fédérale de Lausanne EPFL, CH-1015 Lausanne, Switzerland \\ b Chemical and Nuclear Engineering Department, Universitat Politècnica de València, Spain
}

\section{A R T I C L E I N F O}

\section{Article history:}

Received 29 May 2012

Received in revised form

22 October 2012

Accepted 22 November 2012

Available online 5 December 2012

Keywords:

CoCrMo alloys

Bio-tribology

Joint prostheses

Corrosion-wear

Electrochemistry

Wear modelling

\begin{abstract}
A B S T R A C T
A good biocompatibility, excellent mechanical properties and high corrosion resistance characterize CoCrMo alloys. Therefore they are widely used for artificial joints in biomedical implants. However, the degradation of the implants during service life leads to the release into the body of toxic ions and wear particles. This continuous degradation is of concern for long-term stability of the implants. Published literature has highlighted the relevance of lubrication as well as metallurgical and contact mechanical factors on the degradation of CoCrMo implant alloys. Recent experimental investigations have proposed tribocorrosion, i.e., the interplay of mechanical wear and corrosion by the body fluids, as one of the crucial degradation mechanism of implants. Tribocorrosion is sub-discipline of tribology and corrosion that recently made significant progresses in mechanistic understanding and modelling. The present work aims at evaluating published results on the degradation of CoCrMo alloys using existing tribocorrosion concepts. Results show that wear accelerated corrosion due to mechanical removal of the passive film during sliding is a major contribution to the overall degradation. Further, a transition from low $\left(10^{-6} \mathrm{~N} / \mathrm{mm}^{3} \mathrm{~m}\right)$ to high $\left(10^{-4} \mathrm{~N} / \mathrm{mm}^{3} \mathrm{~m}\right)$ wear coefficients was found at a threshold electrode potential close to $0.2 V_{\mathrm{SHE}}$ These findings clearly show that electrochemical phenomena play a key role on the tribological behaviour of biomedical CoCrMo alloy implants.
\end{abstract}

(c) 2012 Elsevier B.V. All rights reserved.

\section{Introduction}

Detachment of wear particles is one of the main problems associated to total hip replacements. Wear debris, especially UHMWPE particulates from Metal-on-Polymer (MoP) joints, may cause aseptic loosening [1]. In order to overcome or minimize this problem alternative bearings such as Metal-on-Metal (MoM) prostheses, including CoCrMo components, have been developed. Second generation MoM bearings were introduced in the early 1990s and were manufactured with improved properties, mainly better clearance [2]. This led to better lubrication compared to first generation MoM articulations [3] and to 10-year survival rates generally exceeding $90 \%$. However, material release from CoCrMo implants has been reported. For example, increasing concentrations of $\mathrm{Co}$ and $\mathrm{Cr}$ were found in blood, in serum and in urine of as well as nano-wear particles in the size range of 6 to $834 \mathrm{~nm}$ were found postoperatively in patients having CoCrMo MoM prostheses [4-6]. Such findings raise concerns about the long term stability of MoM implants. Indeed, wear products from metallic implants are potentially harmful to the surrounding

\footnotetext{
*Corresponding author. Tel.: +412169329 54; fax: +4121693 3946 .

E-mail address: stefano.mischler@epfl.ch (S. Mischler).
}

tissue [5,6]. Co- and $\mathrm{Cr}$-ions are considered to be toxic or even carcinogenic and have been shown to promote inflammation and reduced cell activity $[7,8]$.

Therefore, even if those alloys account among the most wear and corrosion resistant ones, there is a need for a better understanding and control of the factors and mechanisms controlling material release from CoCrMo implants. Examination of retrievals $[9,10]$ have shown that the determining mechanisms of MoM joint degradation are complex and depend on a variety of interactions between mechanical, chemical, electrochemical and physical parameters. Clear evidence of wear and corrosion has been detected in explants [11] where metal debris was generated by the combined effect of these two degradation mechanisms. Abrasion and tribochemical reactions in the articulating surfaces which modifies in-vivo wear behaviour of prostheses have also been reported [12-14]. The degradation of metal-on-metal (mainly CoCrMo) artificial joints has been the object of an increasing number of scientific in-vitro investigations. Aspects such a lubrication, clearance, wear patterns and mechanical testing methods have been throughout analysed and reviews are available [2,15-17]. Rieker et al. [2] studied the relationship between clearance and linear wear rate for MoM bearings and found that the wear rate decreased with decreasing clearance down to a minimum value specific for a given particular design of 
the MoM articulation. Existing lubrication and wear models have been reviewed by Mattei et al. [16] who pointed out the need for more elaborate approaches including both phenomena and their interaction. Affatato et al. [17] critically evaluated the current practice of testing materials through in-vitro joint simulators. Those authors concluded that extrapolation of short-term simulator results to long-term in-vivo situations requires a solid understanding of the basic wear mechanisms. This could be achieved by a parametric study that, due to the large number of parameters to be investigated, should be carried out by a number of laboratories sharing a common test protocol.

Recently, increasing attention has been paid to possible effects of tribocorrosion, i.e., the deterioration or modification of contacting metals due to the simultaneous action of wear and corrosion [18-22]. The pertinence of a tribocorrosion approach to the degradation of a wide range of biomedical implants has been recently shown by Mathew et al. [21]. Specific tribocorrosion issues in total joint replacement have been discussed by Neville and Yan [23] and Mathew and Wimmer [24,25]. The former authors concluded that the tribocorrosion research still needs to be developed in order to answer specific questions such as the role of protein on MoM degradation. Mathew et al. [24,25] pointed out the lack of standardized experimental approaches to biotribocorrosion situations despite the clear evidence of in-vivo tribocorrosion phenomena.

Tribocorrosion is a relatively young discipline at the intersection between tribology and corrosion science that is experiencing fast development. Dedicated experimental devices based on the combination of electrochemical and tribological techniques have been continuously developed and validated in the past [26-28]. Mechanistic models describing quantitatively the extent of tribocorrosion damage have been proposed [29-32] and reviewed [33]. All those models highlight the interaction of load, electrochemical and material parameters that determine tribocorrosion degradation. However, no attempt to apply those tribocorrosion models to CoCrMo hip joints has been reported.

This study was initiated with the aim to compare published data on degradation of CoCrMo contacts in simulated body fluids with existing models of tribocorrosion in an attempt to evaluate their pertinence for artificial hip joints and to identify shortcomings and needs for future developments. A literature search was carried out in order to gather the necessary quantitative information on wear of CoCrMo in simulated body fluids. In addition to mechanical and material conditions the electrochemical test conditions and the corrosion response of the investigated systems were analyzed. The existing tribocorrosion concepts and models are briefly presented in the first section and tentatively used to rationalize published results on wear of CoCrMo on CoCrMo total joint replacements.

\section{Tribocorrosion}

\subsection{Tribocorrosion mechanisms}

Tribocorrosion is a material transformation or degradation due to the combined action of wear and corrosion. Because of the interaction of chemical and mechanical factors, tribocorrosion is not simply the sum of corrosion and wear taken separately. Indeed, surface films may influence the mechanical response of contacting metals while the scraping of protective films can significantly accelerate corrosion.

Tribocorrosion involves different degradation phenomena (corrosion, wear accelerated corrosion and wear) depending on duty cycle (locomotion, rest phase) and location (bearing area, structural parts). Corrosion occurs on the whole metal surface exposed to the corrosive fluids while wear accelerated corrosion and mechanical wear occur only on area subject to sliding, i.e., the joint bearing area (the head-cup contact in hip joints) in orthopaedic implants. The different mechanisms are schematically illustrated in Fig. 1.

As other biomedical alloys (i.e., titanium and its alloys, stainless steels) CoCrMo alloys are passive, i.e., they form spontaneously by contact with water a thin surface oxide layer (typically 2 to $10 \mathrm{~nm}$ thin) that significantly slows down the corrosion rate.

Sliding against a counter body can locally remove the passive films thus exposing highly reactive bare metal to the environment and enhancing the corrosion rate (wear accelerated corrosion). The loss of passivity under sliding conditions can occur as a consequence of spalling off of the passive film or of the metal and of plastic deformation of the metal. The exposed bare metal repassivates usually in a short time during which however metal can corrode. Further, sliding can result in mechanical wear associated with the detachment and release of metal particles. Despite the mechanical nature of this process, corrosion can significantly affect it. For example passive films may render metals brittle and prone to wear (Roscoe effect [34]). Corrosion products may act as lubricant, as in the case of phosphate ions [Garcia].

\subsection{Wear accelerated corrosion of passive metals}

Studies of wear accelerated corrosion of passive metals are usually carried out by imposing a passive electrode potential to the metal while rubbing against a counter piece. In this way, the acceleration of corrosion can be measured by recording the current necessary to maintain the passive potential. Details of this technique are given elsewhere [26].

Models were already developed to describe the current generated during wear accelerated corrosion [31]. The models are based on the Archard approach and assume that plastic deformation occurs at the asperity junction established between the contacting materials. The plastic deformation of the asperities implies the local breaking down of the passive film and fresh metal reaching the contact surface. Sliding generates new asperities junctions on the surface entering the contact while the fresh metals created during contact at junctions oxidizes upon exposure to the solution. This continuous process of local depassivation/repassivation yields

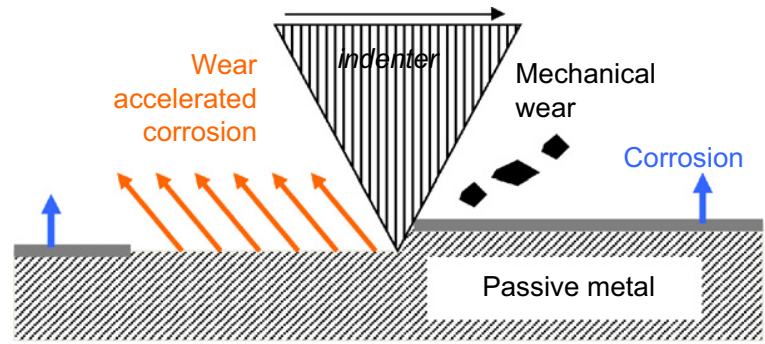

Fig. 1. Schematic illustration of the degradation mechanisms of passive metals subject to tribocorrosion.

Table 1

Values of $k$ and $b$ parameters in Eq. (1) as a function of contact geometry.

\begin{tabular}{llll}
\hline Case & Geometry & $\mathrm{k}$ & $\mathrm{b}$ \\
\hline A & Rough metal vs. rough counter body & $0.89 k^{\prime} n_{\mathrm{f}}^{0.5}$ & 0.5 \\
B & Smooth metal vs. rough counter body & $1.12 k^{\prime} n_{\mathrm{f}}^{0.5}(\cos \alpha)$ & 0.5 \\
C & Rough metal vs. rough smooth body & $k^{\prime} / \lambda$ & 1
\end{tabular}

$k^{\prime}$ : probability factor, $n_{f}:$ number of asperities in simultaneous contact, $\alpha$ : average attack angle of asperities, $\lambda$ : length of the smooth body in sliding direction. 
a steady state overall wear accelerated corrosion current I described by Eq. (1).

$I_{\mathrm{r}}=k v_{\mathrm{s}} Q\left(F_{\mathrm{n}} / H\right)^{b}$

where $k$ is a proportionality factor, $v_{\mathrm{s}}(\mathrm{m} / \mathrm{s})$ is the sliding velocity, $Q\left(\mathrm{As} / \mathrm{m}^{2}\right)$ is the passivation charge density (the anodic charge needed to repassivate the bare metal surface), $F_{\mathrm{n}}$ the normal force $(N)$ and $H$ the metal indentation hardness $(\mathrm{Pa})$. The values of $k$ and of the exponent $b$ vary depending on the contact geometry as described in Table 1.

The factor $k$ (see Table 1 for their definition) depends on parameters such as $n_{\mathrm{f}}$ (number of asperities in simultaneous contact) that are difficult to estimate and therefore Eq. (1) can hardly be used for quantitative predictions. Instead, this equation permits the appraisal of the influence of electrochemical, mechanical and material properties on wear accelerated corrosion. The parameter $Q$ is related to the passivation reaction kinetics and thus depends on the electrochemical conditions established within the contact. In the tests under applied potential these conditions can be controlled or, at least, kept stable.

\subsection{Influence of rubbing on the electrochemical conditions}

Most of the tribocorrosion systems operate without an externally imposed electrode potential. In such situations a potential difference (the so called corrosion potential $E_{\text {cor }}$ or sometime called Open Circuit Potential) spontaneously establishes between metal and surrounding solutions depending on surface oxidation state, solution composition, temperature, flow conditions and others. Under rubbing conditions the passive film is locally removed thus exposing bare metal to the solution. The $E_{\text {cor }}$ of the bare metal differs from the potential of the surrounding passive areas since its oxidation kinetics is much higher. As a consequence a galvanic coupling forms between passive and depassivated zones. The $E_{\text {cor }}$ of the abraded metal and thus wear accelerated corrosion depends on this galvanic coupling.

This effect can best be visualized using the Evans diagrams (Fig. 2) representing the evolution of the current density (reaction rate) of the cathodic (reduction of dissolved oxygen for example) and anodic reaction (metal oxidation) as a function the electrode potential. In absence of rubbing $E_{\text {cor }}$ (Fig. 2a) corresponds to the intersection of the cathodic and the anodic curves. The rubbed areas experience an increase in metal oxidation rate because the loss of passivity. Therefore their theoretical corrosion potential is expected to move towards more cathodic values ( $E_{\text {cor }}{ }^{\prime}$ in Fig. $2 b$ ). However, since the depassivated and still passive areas are in electronic contact, a galvanic coupling occurs. In an ideal short circuit condition the two areas would reach the same potential situated in between $E_{\mathrm{cor}}$ and $E_{\mathrm{cor}}$. However, due to the finite ionic resistance $R$ of the solution a difference in potential, given by the product of R time the current $I_{\mathrm{r}}$, is maintained between depassivated and passive areas, which attain the potentials $E_{\mathrm{a}}$ and $E_{\mathrm{c}}$, respectively (Fig. $2 \mathrm{c}$ ).

Based on this approach, Vieira et al. [35] developed a simple galvanic coupling model for describing the potential of depassivated $\left(E_{\mathrm{a}}\right)$ and passive $\left(E_{\mathrm{c}}\right)$ areas created during rubbing (Eqs. (2) and (3)).

$E_{\mathrm{c}}=E_{\mathrm{corr}}+a_{\mathrm{c}}-b_{\mathrm{c}} \times \log \left(i_{\mathrm{a}} \times A_{\mathrm{a}} / A_{\mathrm{c}}\right)$

$E_{\mathrm{a}}=E_{\mathrm{c}}-R I_{\mathrm{r}}$

where $a_{\mathrm{c}}$ and $b_{\mathrm{c}}$ are kinetics parameters of the reduction reaction (Tafel constants), $A_{\mathrm{a}}$ and $A_{\mathrm{c}}$ are the surface areas of the depassivated and passive zones, respectively and $i_{\mathrm{a}}$ is the anodic current density (wear accelerated corrosion rate) established in the worn areas. This latter parameter can be rewritten as

$i_{\mathrm{a}}=I_{\mathrm{r}} / A_{\mathrm{a}}$

where $I_{\mathrm{r}}$ is the current during rubbing. $R$ is the solution resistance between the anode and cathode. The first three parameters of Eq. (2) can be extracted from independent electrochemical experiments such as polarisation curves. Three limiting cases can be considered when determining $A_{\mathrm{a}}$ and $A_{\mathrm{c}}$. In one case $A_{\mathrm{a}}$ corresponds to the wear track area when rubbing leads to complete depassivation of the rubbing affected area. This is typically the case of metals covered by friable passive films. In this case $A_{c}$ is the rest of the metal surface exposed to the solution [35]. In such situations $A_{\mathrm{a}}$ and $A_{\mathrm{c}}$ can be determined with a

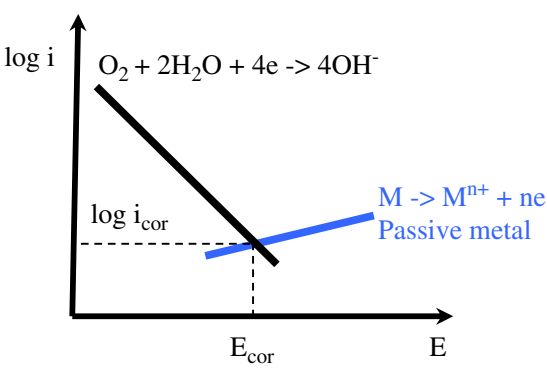

b

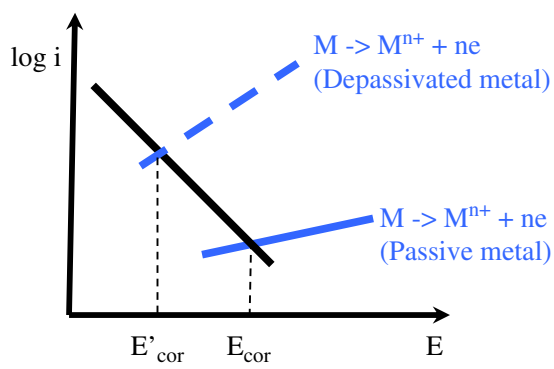

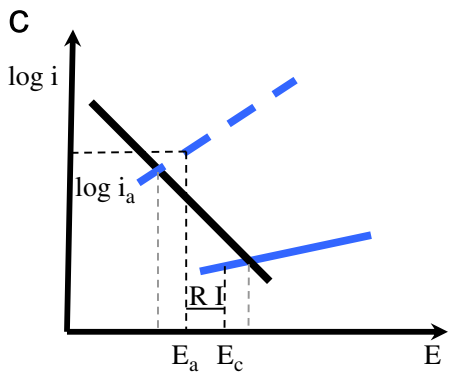

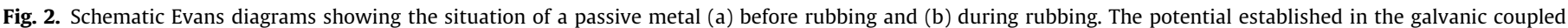
passive and depassivated worn areas are shown in (c). Explanations are given in the text. 
reasonable precision during and at the end of the tribocorrosion experiment. Another limiting case is when depassivated and still passive areas coexist within the wear track. This is the case of well adhering passive films. In this case $A_{\mathrm{a}}$ would be a fraction of the wear track area. In case of low conductivity electrolytes galvanic coupling occurs only at short range at the edges of the wear track. In the latter two cases the determination of $A_{\mathrm{a}}$ and $A_{\mathrm{c}}$ is problematic. In principle $I_{\mathrm{r}}$ can be determined from Eq. (1) provided the proportionality factor $k$ and the passivation charge density $Q$ which is itself a function of the potential, are known. The determination of $I_{\mathrm{r}}$ is therefore complex and requires usually dedicated experiment such as potentiostatic tribocorrosion tests [26].

The above described theoretical approach is supported by a large amount of experimental observations showing that the electrode potential shifts towards lower values at the onset of rubbing [26]. Note that in most of the laboratory test devices the reference electrode used to measure the electrode potential is located at a certain distance from the rubbed area (which is usually a small fraction of the sample area). Therefore the measured potential is thought to correspond quite closely to $E_{\mathrm{c}}$. Vieira et al. [35] applied the model to the tribocorrosion of aluminium alloys (alumina antagonist). Assuming a completely depassivated wear track $\left(A_{\mathrm{a}}\right)$ this simple model provided an accurate description of the evolution of potential during rubbing in $\mathrm{NaCl}$ solutions. However, under this assumption the model could not be applied for $\mathrm{NaNO}_{3}$ solutions probably because passive zones were still maintained within the wear track due to the higher hardness of the passive film [30]. Clearly, this model needs further validation. Nevertheless it constitutes a promising predictive tool for evaluating the electrochemical conditions in a tribocorrosion system.

\subsection{Influence of electrochemical conditions on the mechanical response of contacting metals}

Only a limited number of studies reported the crucial role played by the electrode potential on the mechanical and wear behaviour of metals and ceramics in tribocorrosion conditions [36-40]. The electrochemical conditions prevailing in the contact determine the surface chemistry of the material (thickness and composition of the passive layer) and may thus influence the mechanical response of contacting metals. A striking example of that is given by the results obtained by Stojadinovic et al. [41] while investigating the tribocorrosion response of Ruthenium in sulphuric acid as a function of potential. They observed sharp wear transitions of one order magnitude on narrow ranges of potential depending on the stability domains of different types of Ruthenium oxide. Note, that in this case the contribution of wear accelerated corrosion on overall degradation was found negligible.

A series of papers $[38,39,42]$ investigated the subsurface deformation of austenitic stainless steels rubbing against alumina in sulphuric acid. Those authors observed the rapid development of a nanocrystalline layer right below the wearing surface. i.e., a structure very close to the one found by Büscher et al. [12] on CoCrMo explanted hip joints. The results on stainless steel clearly indicated that passive potentials generate larger subsurface deformation and mechanical wear compared to cathodic potentials where no surface films form. This effect was attributed to the passive film interfering with the generation and elimination of dislocations. However, these effects need further elucidation and validation on different systems in order to be included in tribocorrosion models [33]. For the time being predictions of mechanical wear are based essentially on Archard's law [32,43] that does not consider electrochemical effects.

\section{Literature review}

\subsection{Strategy for literature search}

The literature search has been carried out by using the keywords "Tribocorrosion", "wear" and "CoCrMo" from 2000 in the following data bases: ISI web of knowledge, Electrochemical Society (ECS), Medline and Science Direct. The results have been presented in two different tables according to the experimental set-up involved, biomedical simulators (Table 2) and laboratory tribometers (Table 3 ). For this only papers providing results obtained under well defined conditions, essentially on hip joint simulators or tribometers, were considered. Laboratory tests such as fretting and micro-abrasion were disregarded because they imply tribological situations not directly applicable to artificial hip joints. Indeed only sliding conditions established in hip joint simulators or in tribometers were considered.

\subsection{Simulators}

Simulators are devices intended to test components of similar geometry and size as the actual implants. The contact in simulators involves concave/convex contacts between the femoral head and the acetabular cup. The forces and displacements imposed during a single cycle are variable and are supposed to mimic the real complex conditions of a joint, which are for example described by Paul [44] and Johnston [45]. The motion is typically a sinusoidal multiaxial rocking motion intended to reproduce flexion/extension, abduction/adduction and rotation of real joints during a walking step. The load varies typically from few hundred Newton up to $3400 \mathrm{~N}$ during a gait cycle. The number of loading cycles varies typically from 3 up to 10 Mcycles at frequencies of 1 or $1.13 \mathrm{~Hz}$. Table 2 summarizes the key features of published papers on the characterisation of metal on metal CoCrMo artificial hip joints using simulators [12,46-58]. Among the authors, only Yan [49] measured the evolution of open circuit potential during a simulator test. In both sodium chloride and bovine serum solution sliding corresponded to a shift from a initial OCP of approximately $-0.05 V_{\text {SSE }}$ toward more cathodic values around $-0.2 V_{\text {SSE. This }}$ behaviour is usually considered as indicative of local depassivation causing galvanic coupling between passive metal areas and areas where the passive film was removed by friction.

For comparison purposes the average pressure, sliding velocity and wear coefficient were extracted, whenever possible, from the reported data. The average Hertzian pressure was calculated using the approximate formulae for convex/concave elliptical contacts found in literature [59]. The input parameters were the load (taken as the mean value between the maximum and the minimum value attained during a cycle), the radius of the femoral head, the clearance between femoral head and acetabular cup and the elastic properties of the CoCrMo alloy (elastic modulus $E=248 \mathrm{GPa}$, Poisson module 0.3). The extracted average Hertzian contact pressure varied between 14 and $60 \mathrm{MPa}$. The average velocity was calculated by considering the maximum angular motion amplitude, the radius of the component and the oscillation frequency. The wear coefficient, characterising the metal volume removed by unit slid length and by unit applied load, was calculated by diving the wear volume reported in the paper by the mean normal force and by the product of sliding velocity, number of cycles and the inverse of the oscillation frequency. The obtained values are very low (from $10^{-9}$ up to $10^{-7} \mathrm{~mm}^{3} / \mathrm{N} \mathrm{m}$ ) although scattering is very large as it ranges over two orders of magnitudes. This scattering reflects the diversity of the experimental conditions as well as the occurrence of wear transitions during tests. 
Table 2

Investigations on CoCrMo alloys using hip joints simulators.

\begin{tabular}{|c|c|c|c|c|c|c|c|c|c|}
\hline Ref. & Femoral head & Acetabular cup & $\begin{array}{l}\text { Diameter } \\
\text { (r clearance })[\mathrm{mm}]\end{array}$ & Solution $^{\mathrm{a}}$ ) & $\left.\operatorname{Load}^{\mathrm{b}}\right)[\mathrm{N}]$ & $\begin{array}{l}\text { Calc. avg } \\
\text { pressure }^{\mathrm{c}} \text { ) [MPa] }\end{array}$ & $\begin{array}{l}\left.\text { Avg speed }^{\mathrm{d}}\right) \\
{[\mathrm{mm} / \mathbf{s}]}\end{array}$ & $\begin{array}{l}\text { Duration [Mcycles] } \\
\text { (Frequency) }\end{array}$ & $\begin{array}{l}\text { Wear coefficient } \\
{\left[\mathrm{mm}^{3} / \mathbf{N} / \mathbf{m}\right]}\end{array}$ \\
\hline 2010 Kretzer & Cast, HC & self mated & $\begin{array}{l}47(0.0972) \\
47(0.0539)\end{array}$ & $\mathrm{S}\left(\mathrm{EDTA}, \mathrm{NaN}_{3}\right)$ & $300-3000$ & $\begin{array}{l}37 \\
25\end{array}$ & 17 & $3(1 \mathrm{~Hz})$ & $\begin{array}{l}1 \times 10^{-9} \min \\
7.4 \times 10^{-8} \max \end{array}$ \\
\hline 2009 Leslie & ASTM F75, HC & self mated & $\begin{array}{l}39(0.063) \\
55(0.053)\end{array}$ & $\mathrm{BS},\left(\mathrm{NaN}_{3}\right)$ & $280-3000$ & $\begin{array}{l}35 \\
20\end{array}$ & $\begin{array}{l}15 \\
18\end{array}$ & $10(1 \mathrm{~Hz})$ & $\begin{array}{l}1.6 \times 10^{-8} \\
7 \times 10^{-9}\end{array}$ \\
\hline 2009 Bowsher & ASTM F75, Cast, HC & self mated & $60(0.118)$ & BCS (EDTA) & $200-2200$ & 27 & & 5 & \\
\hline 2009 Yan & & self mated & $36(?)$ & $\mathrm{NaCl}, \mathrm{BS}$ & $300-2000$ & & 16 & & \\
\hline 2006 Unsworth & & self mated & $28(0.04)$ & $\mathrm{BS}, \mathrm{CMC}$ & $100-2000$ & 35 & 5 & & $9.5 \times 10^{-8}$ \\
\hline 2006 Brockett & & self mated & $28(0.029)$ & $\begin{array}{l}\text { Water, } 25 \% \mathrm{CS}\left(0.1 \% \mathrm{NaN}_{3}\right) \text {, } \\
100 \% \mathrm{BS}\end{array}$ & $25-2000$ & 28 & 12 & & \\
\hline 2005 Rieker & $\begin{array}{l}\text { ISO } 5832-12 \text {, wrought, } \\
\text { forged, } \mathrm{HC}\end{array}$ & self mated & $38(0.049)$ & $33 \% \mathrm{CS}$ in $\mathrm{R}$ & $0 ?-3000$ & 30 & 14 & 5 & \\
\hline & & & $38(0.139)$ & & & 60 & 14 & & \\
\hline & & & $50(0.072)$ & & & 27 & 19 & & \\
\hline & & & $50(0.132)$ & & & 40 & 19 & & \\
\hline & & & $54(0.033)$ & & & 14 & 20 & & \\
\hline & & & $56(0.119)$ & & & 32 & 21 & & \\
\hline 2004 Fisher & ASTMF-1537-94, Wrought, LC & ASTMF-1537-94, Wrought, HC & $(0.03)$ & $25 \% \mathrm{BS}\left(\mathrm{NaN}_{3}\right)$ & $0 ?-3000$ & & & $5(1 \mathrm{~Hz})$ & \\
\hline 2004 Büscher & ISO 5832-12 Wrougth, LC & self mated & & $\mathrm{SF}$ & $\max 2000$ & $<50$ & $<200$ & & \\
\hline 2004 Catelas & ASTM F75, Cast & self mated & $28(0.031)$ & 95\% BCS (antibiotics, EDTA) & 3400 peak & 35 & & $3(1.13 \mathrm{~Hz})$ & \\
\hline 2003 St. John & ASTM F1537, HC & self mated & $28(0.044)$ & BCS (EDTA) & 3000 & 42 & & $2.5(1 \mathrm{~Hz})$ & $4 \times 10^{-9}$ \\
\hline 2003 Catelas & $\begin{array}{l}\text { ASTM F1537, Wrought, } \\
\text { HC and LC, ASTM F75-92, Cast }\end{array}$ & self mated & $28(0.018)$ & 95\% BCS (antibiotics, EDTA) & 3400 & 24 & & $3(1.13 \mathrm{~Hz})$ & $8 \times 10^{-9}$ \\
\hline 2001 Firkins & $\begin{array}{l}\text { ASTM F1537, } \\
\text { Wrought, LC }\end{array}$ & ASTM F1537, Wrought, HC & $\begin{array}{l}28(0.031) \\
28(0.030)\end{array}$ & $25 \% \mathrm{BS}\left(\mathrm{NaN}_{3}\right)$ & 3000 & $\begin{array}{l}34 \\
33\end{array}$ & & $5(1 \mathrm{~Hz})$ & $\begin{array}{l}4 \times 10^{-8} \\
4.4 \times 10^{-8}\end{array}$ \\
\hline 2000 Scholes & & Self mated & $28(0.040)$ & $\mathrm{BS}, \mathrm{CMC}$ & $100-2000$ & 35 & 7 & & $1.1 \times 10^{-7}$ \\
\hline
\end{tabular}

a Solution: S Serum; BS Bovine Serum, BCS Bovine Calf Serum, CS Calf Serum, CMC Carboxyl-Methyl-Cellulose, R Ringer's solution, SF Synovial Fluid.

${ }^{\mathrm{b}}$ In absence of indication the minimum force was assumed to be 0 .

c Pressure was calculated assuming a force corresponding to the mean value between maximum and minimum reported force.

${ }^{\mathrm{d}}$ Estimated assuming a constant speed during a cycle. 
Investigations on CoCrMo alloys using tribometers.

\begin{tabular}{|c|c|c|c|c|c|c|c|c|c|}
\hline Ref. & CoCrMo alloy & $\begin{array}{l}\text { Counter part } \\
\text { (Diameter) }[\mathrm{mm}]\end{array}$ & $\begin{array}{l}\text { Motion contact } \\
\text { geometry }\end{array}$ & Solution $^{\mathbf{a}}$ ) & $\begin{array}{l}\text { Load }[\mathrm{N}] \\
\text { (Avg press) [MPa] }\end{array}$ & $\begin{array}{l}\text { Avg speed } \\
{[\mathrm{mm} / \mathrm{s}]} \\
\text { (Duration) [s] }\end{array}$ & $\begin{array}{l}\text { Electrochem. } \\
\text { control }\end{array}$ & $\begin{array}{l}\text { Friction } \\
\text { range }\end{array}$ & $\begin{array}{l}\text { Wear } \\
\text { coefficient } \\
{\left[\mathrm{mm}^{3} / \mathrm{Nm}\right]}\end{array}$ \\
\hline 2011 Igual & ASTM153HC, LC & $\mathrm{Al}_{2} \mathrm{O}_{3}$ ball $(6)$ & Reciprocating Ball on plate & $\mathrm{NaCl}, \mathrm{NaCl}+\mathrm{BSA} \mathrm{PBS}, \mathrm{PBS}+\mathrm{BSA}$ & $1.2(550)$ & $10(3,600)$ & $\begin{array}{l}\text { Applied } \\
\text { potential }\end{array}$ & $0.4-1$ & $\begin{array}{l}1.8 \times 10^{-5} \\
5.6 \times 10^{-5}\end{array}$ \\
\hline 2011 Casaban & ASTM F75, HC & $\mathrm{Al}_{2} \mathrm{O}_{3}$ ball $(6)$ & Unidirectional Ball on plate & $\mathrm{NaCl}, \mathrm{BS}$ & $5(886)$ & $20(3,600)$ & $\begin{array}{l}\text { Applied } \\
\text { potential }\end{array}$ & & $\begin{array}{l}1.4 \times 10^{-6} \\
8.3 \times 10^{-5}\end{array}$ \\
\hline 2010 Santos & ASTM 1537 & $\mathrm{Al}_{2} \mathrm{O}_{3}$ ball & Reciprocating Ball on plate & PBS & 15 & $10(7,230)$ & Potential sweep & $0.15-0.3$ & \\
\hline 2010 Casaban & ASTM F75, HC & $\mathrm{Al}_{2} \mathrm{O}_{3}$ ball $(6)$ & Unidirectional Ball on plate & $\mathrm{NaCl}, \mathrm{BS}$ & $5(886)$ & $20(3,600)$ & $\begin{array}{l}\text { Applied } \\
\text { potential }\end{array}$ & & $\begin{array}{l}3.3 \times 10^{-6} \\
8.3 \times 10^{-6}\end{array}$ \\
\hline 2008 Mishina & CoCrMo & $\begin{array}{l}\text { CoCrMo flat } \\
\text { pin }(4)\end{array}$ & Unidirectional Flat on plate & PBS, PBS + BSA & $30(2.4)$ & $52(86,400)$ & & $0.03-0.2$ & \\
\hline 2007 Chiba & $\begin{array}{l}\text { ASTM F75 HC, } \\
\text { Forged LC }\end{array}$ & $\begin{array}{l}\text { Self mated, } \\
\text { flat pin }(6)\end{array}$ & Undirectional Flat on plate & Hanks & $9.8(3.12)$ & $20(60,4800)$ & & 0.6 & $\begin{array}{l}1.2 \times 10^{-6} \\
3.0 \times 10^{-6}\end{array}$ \\
\hline 2007 Yan 1 & HC, LC & SiN ball (12) & Reciprocating ball on plate & $\mathrm{NaCl}, \mathrm{CS}$ & $80(1300)$ & $20(15,000)$ & $\begin{array}{l}\text { Applied } \\
\text { potential }\end{array}$ & $0.15-0.8$ & $\begin{array}{l}4.2 \times 10^{-7} \\
2.9 \times 10^{-6}\end{array}$ \\
\hline 2007 Yan 2 & HC, LC & SiN ball (12) & Reciprocating Ball on plate & $\mathrm{NaCl}$, DMEM & $80(1300)$ & $20(15,000)$ & $\begin{array}{l}\text { Applied } \\
\text { potential }\end{array}$ & $0.2-0.8$ & $\begin{array}{l}1.7 \times 10^{-6} \\
4.1 \times 10^{-6}\end{array}$ \\
\hline 2007 Iwabuchi & CoCrMo & $\mathrm{Al}_{2} \mathrm{O}_{3}$ ball $(6)$ & $\begin{array}{l}\text { Reciprocating } \\
\text { Ball on plate }\end{array}$ & $\begin{array}{l}\mathrm{Hanks,} \mathrm{H}_{2} \mathrm{O} \\
\mathrm{Na}_{2} \mathrm{SO}_{4}\end{array}$ & $11(1152)$ & $20(5,400)$ & $\mathrm{OCP}$ & $0.05-0.3$ & $2 \times 10^{-6}$ \\
\hline 2007 Mitchell & ASTM F75 & $\begin{array}{l}\mathrm{Si}_{3} \mathrm{~N}_{4} \mathrm{AFM} \text { tip, } \\
(100 \mathrm{~nm})\end{array}$ & $\begin{array}{l}\text { Tip on plate Repeated } \\
\text { scratching }\end{array}$ & air 50RH & $\begin{array}{l}2 \times 10^{-9}(900) \text { to } \\
75 \times 10^{-9}(3700)\end{array}$ & $0.02(900)$ & & & \\
\hline 2006 Yan 1 & HC, LC & SiN ball (12) & Reciprocating Ball on plate & $\mathrm{BS}, \mathrm{NaCl}, \mathrm{DMEM}$ & $80(1300)$ & & $\begin{array}{l}\text { Applied } \\
\text { potential }\end{array}$ & $0.15-0.8$ & $\begin{array}{l}2 \times 10^{-6} \\
6 \times 10^{-6}\end{array}$ \\
\hline 2006 Yan 2 & HC, LC & SiN ball (12) & Reciprocating Ball on plate & $\mathrm{BS}, \mathrm{NaCl}, \mathrm{DMEM}$ & $80(1300)$ & $\begin{array}{l}20(\max ) \\
(15,000)\end{array}$ & $\begin{array}{l}\text { Applied } \\
\text { potential }\end{array}$ & $0.2-0.8$ & $\begin{array}{l}2 \times 10^{-6} \\
6 \times 10^{-6}\end{array}$ \\
\hline 2006 Yan 3 & HC, LC & SiN ball (12) & Reciprocating Ball on plate & BS & $80(1300)$ & 20 & $\mathrm{OCP}$ & $\begin{array}{l}0.15- \\
0.25\end{array}$ & $\begin{array}{l}2 \times 10^{-6} \\
6 \times 10^{-6}\end{array}$ \\
\hline 2006 Varano & $\begin{array}{l}\text { ASTM F1537 LC, } \\
\text { HC, } \\
\text { ASTM F75 }\end{array}$ & $\begin{array}{l}\text { Self mated pin } \\
(200)\end{array}$ & Reciprocating Ball on plate & $\begin{array}{l}\text { BCS +EDTA+ } \\
\text { Fungizone+ } \\
\text { Streptomycin }\end{array}$ & $9.81(97)$ & $26(86,4000)$ & & & $\begin{array}{l}9 \times 10^{-7} \\
5.5 \times 10^{-6}\end{array}$ \\
\hline 2005 Spriano & CoCrMo & $\mathrm{Al}_{2} \mathrm{O}_{3}$ ball $(6)$ & Unidirectional Ball on plate & $\mathrm{BS}\left(\mathrm{NaN}_{3}\right)$ & $5(865)$ or $7(1150)$ & 100 & & $\begin{array}{l}0.18- \\
0.23\end{array}$ & $\begin{array}{l}0.7 \times 10^{-4} \\
8 \times 10^{-4}\end{array}$ \\
\hline 2004 Büscher & Forged CoCrMo & $\begin{array}{l}\text { Self mated } \\
\text { pin }(32)\end{array}$ & Unidirectional Ball on plate & Distilled water & $5(370)$ & 100 & - & - & \\
\hline 2003 St. John & ASTM F1537 & $\begin{array}{l}\text { Self mated } \\
\text { pin (32) }\end{array}$ & Reciprocating Ball on plate & BCS (EDTA) & $5.89(165)$ & 30 & - & - & \\
\hline 2003 Büscher & Forged CoCrMo & $\begin{array}{l}\text { Self mated } \\
\text { pin ( } 32)\end{array}$ & Unidirectional Ball on plate & $\mathrm{R}$, distilled water & $5(370)$ & 100 & - & - & \\
\hline 2001 Scholes & $\begin{array}{l}\text { ASTM F1537, F799, } \\
\text { HC and LC, } \\
\text { wrought }\end{array}$ & $\begin{array}{l}\text { Self mated, } \\
\text { flat pin }(5)\end{array}$ & $\begin{array}{l}\text { Reciprocating with/without } \\
\text { rotation } \\
\text { Flat on plate }\end{array}$ & $\mathrm{BS}\left(\mathrm{NaN}_{3}\right)$ & $40(2)$ & 50 & & & $\begin{array}{l}1 \times 10^{-6} \\
6 \times 10^{-6}\end{array}$ \\
\hline 2001 Wimmer & $\begin{array}{l}\text { ISO5832 HC } \\
\text { wrought }\end{array}$ & $\begin{array}{l}2 \text { Self mated pins } \\
(14)\end{array}$ & $\begin{array}{l}\text { Reciprocating biaxial rotation Concave } \\
\text { pin on ball }\end{array}$ & $\begin{array}{l}\text { CS + antibiotics + tris-hydroxy- } \\
\text { methylamine }\end{array}$ & $750(20)$ & 29.3 & - & 0.1 & $2 \times 10^{-7}$ \\
\hline
\end{tabular}

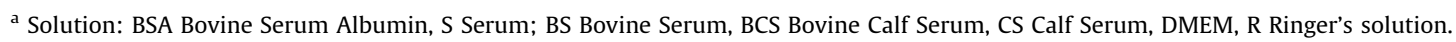


The investigated materials were cast (ASTM F75) or wrought (ASTM F1537 or ISO 5832-12) CoCrMo alloys with $28 \% \mathrm{Cr}$ and $6 \%$ Mo. Two classes of alloys were also considered according to the carbon content: low carbon alloys ( $C$ content $<0.05 \%$ ) and high carbon alloys ( $\mathrm{C}$ content $>0.15$ ). The low carbon alloys (LC) present a homogeneous structure while the high carbon alloys (HC) are characterised by carbides precipitation [60-62] which function is to increase mechanical strength and, to a lesser extent, hardness. Most of the contacts were self mated except in two cases where a combination of low carbon (femoral head) and high carbon (acetabular cup) wrought alloys was used [53,57].

All authors used bovine serum based solutions as lubricant in their tests. With approximately 40 components [63] bovine serum is a very complex liquid with a broad reactivity spectrum. It is seldom used without additions of biocides (such as sodium azide $\mathrm{NaN}_{3}$ ) and complexing agents (such as EDTA) to avoid metal precipitation [46-48,51,53-57]. Moreover, it can be used at different dilutions in water [51] or Ringer's solutions [52] depending on laboratory. All these differences are likely to influence the rheological, chemical and frictional properties of the lubricant and thus render difficult the comparison of results obtained by different laboratories. Some authors used alternative lubricants. Unsworth [50] and Scholes [58] used carboxyl-methylcellulose (CMC) to avoid chemical reactivity of bovine serum and reproducing the viscosity of synovial fluids. Comparison with bovine serum solutions showed that CMC increases friction in case of metal-on-metal couples but reduces it in self mated ceramic joints as well as in case of metal on polymer contacts $[50,58]$. Brockett [51] compared the frictional properties of water with different concentrations in bovine serum and found that friction decreases with increasing serum concentration. This effect was attributed to solid phase lubrication by surface proteins and/or by hydrodynamic effects. Yan [61] investigated material release and friction of CoCrMo self mated contact in a simple $\mathrm{NaCl}$ solution and in bovine serum. It was found that bovine serum provides lower friction but higher material release rate. This result suggests that mechanical effects alone cannot account for material deterioration processes that are likely also influenced by chemical effects. Indeed, Büscher reported the formation on the sliding surfaces of carbonaceous biofilms similar to those observed in implants after clinical use [12].

Surprisingly lubricant temperature was seldom reported despite its relevance for viscosity and chemical reactivity. Kretzer [46], Rieker [52] and Büscher [12] maintained a lubricant temperature of $37{ }^{\circ} \mathrm{C}$ while Bowsher [48] limited it at around $30^{\circ} \mathrm{C}$. Note however, that temperature can increase in the contact due to frictional heating.

Most of the authors [2,46-48,53,54,56,57] measure the material loss at regular intervals during sliding test. They all reported an initial running in period where most of the wear occurred followed by a steady state with little or no increase in wear. For example Rieker [2] reported a cumulative linear wear of $13.3 \mu \mathrm{m}$ in the first 0.5 Mcycles and of $14.0 \mu \mathrm{m}$ at the end of the test at 5 Mcycles. The transition between run-in and steady state varied significantly depending on reports: value as low as 0.25 Mcycles [48] and as high as 4 Mcycles [52] were reported. Clearly the judgement of wear severity through wear rates must take into account this run-in effect, and in particular the relation between run-in and test duration. Tests lasting for longer time intervals than the run-in period will appear less severe than test stopped during of just after run-in. On the other hand, different conclusions on the effect of a certain parameter can be drawn depending on the number of cycles considered: for example in Rieker's study [2] when taking a short number of cycles clearance appears to promote wear while it has no significant effect after longer periods. Further, if one considers wear severity (wear coefficient or linear wear per cycle) instead of cumulative wear the effect of test duration becomes even more relevant with differences of one order of magnitude depending on considered number of cycles. This example shows that the occurrence of transitions cannot be neglected when analysing wear data, in particular in the case of simulator results.

\subsection{Tribometers}

Tribometers are used for accelerated material evaluation using simpler geometries, such as ball on plate or pin on plate, that are more easily manufactured than simulator components. They usually operate under simple mechanical conditions involving constant loads and unidirectional sliding movements. The lubricants palette used in tribometers is wider than in simulators and ranges from simple saline solutions with or without addition of organic molecules to more complex body fluids including bovine serum or synovial fluids. In research work the tribometers are often coupled with electrochemical set-up that allow monitoring the corrosion response to friction.

Results from published literature on tribocorrosion tests on CoCrMo biomedical alloys are summarized in Table 3 [12,18-20, 55,61,64-77]. Papers [78,79] dealing with soft materials (for example UHMWPE) were not included in the table as they did not brought insights into damage of CoCrMo. Table 3 is characterized by a much larger variability of investigated CoCrMo alloys and test conditions compared to simulator investigations (Table 2). Sample preparation for tribometers is much easier than in the case of simulators using industrial components. This facilitates testing not only a wider range of material compositions but also of microstructures resulting for example from different heat treatments. The flexibility in contact geometry proper to tribometers allows working under a wide spectrum of initial contact pressures, ranging from 2 up to $1300 \mathrm{MPa}$, and using different counter materials (typically ceramic materials). The investigated lubricants include bovine serum as well a variety of body simulating fluids (water, sodium chloride solutions, PBS phosphate buffered solutions, Hank's solutions) with or without addition of proteins. Most of the authors impose a temperature of $37^{\circ} \mathrm{C}$. The type of motion is essentially limited to reciprocating or unidirectional sliding and the sliding velocities are comprised between 10 and $100 \mathrm{~mm} / \mathrm{s}$. Test duration is generally shorter than in simulators and typically does not last longer than few hours. Nearly half of the papers listed in Table 3 reported the use of electrochemical techniques to control or to monitor the corrosion conditions of the contact. The most widely used technique is the potentiostatic one where the electrode potential of the investigated metal is imposed through a three-electrode set-up connected to a potentiostat. This set-up allows also the monitoring of the current and thus, under appropriate conditions, of the corrosion rate. However, the proper interpretation of the current response requires the use of inert counterpart such as silicon nitride or alumina.

In most cases a ball (or hemispherical pin) on flat contact configuration is used to avoid alignment problems that in flat on flat contacts may cause non uniform pressure distributions inside the contact. The disadvantage of ball on flat contacts is that their geometry changes with the progress of wear usually resulting in a decreased pressure. Table 3 lists also the wear coefficients extracted from the published data (in case of multiple results the maximum and minimum values are indicated). The observed wear coefficients vary typically between $10^{-5}$ and $10^{-7} \mathrm{~mm}^{3} / \mathrm{N} \mathrm{m}$. Only Spriano [71] reported wear coefficients in the order of $10^{-4} \mathrm{~mm}^{3} / \mathrm{N} \mathrm{m}$. In all cases except one the wear is measured at the end of the test. Chiba [67], by monitoring wear at regular 
intervals in the curse of experiment, identified in special cases wear transitions similar to the one observed in simulators.

\section{Discussion}

\subsection{Comparison simulators vs. tribometers}

Electrochemical measurements combined with tribological tests are essential in order to appraise wear-corrosion interactions. Such a combination is widely found in studies carried out using tribometers but not, except one paper [49], in simulators. Simulators better represent the in-vivo conditions of implants while tribometers are better suited for accelerated tests under usually more severe mechanical loading. Extrapolation of electrochemical results from tribometers to simulators requires therefore a critical comparison of the tests conditions.

Sliding velocity is an essential factor controlling fluid lubrication. The frequency determines the latency time and thus the extent of metal oxidation (or any other surface reaction) between two successive strokes. Changes in sliding direction may exacerbate wear [73]. Tables 2 and 3 reveal that the ranges of velocity used in tribometers (10 to $100 \mathrm{~mm} / \mathrm{s}$ ) and simulators (20 to $50 \mathrm{~mm} / \mathrm{s}$ ) largely overlap. Also the typical frequencies used in both types of tests are very close to $1 \mathrm{~Hz}$, corresponding to the typical gait frequency [16]. Differences between simulators and tribometers appear in the directionality of motion. The simulators operate in multidirectional mode simulating the natural joint movement while most of the tribometers operate in unidirectional motion [12,19,65-67,71,72]. Multi-directional motion is applied only in three tribometers [73,74]. Scholes et al. [73] found that superposing a rotational movement to the pin in a self mated sliding pin on plate configuration affected significantly the wear of CoCrMo of low carbon content but not the one of high carbon content alloys. The effect of motion's multi-directionality on wear is not well understood and seems to depend on the specific test conditions.

While applied velocities and frequencies do not vary significantly between tribometers and simulators the variety of mechanical loading is much larger. Most of the tribometer studies make use of a ball on plate configuration yielding larger contact pressures than the concave-convex contacts used in simulators. Indeed, in tribometers average contact pressures range from few MPa (flat on flat configurations) to $1300 \mathrm{MPa}$ (ball on flat configurations) while simulators are usually operated in a much narrower range (typically $20 \mathrm{MPa}$ ) reflecting the mechanical conditions established in the implant. The wear coefficients were plotted in Fig. 3 as s function of contact pressure (data from Tables 2 to 3 ).

The analysis of the data obtained through tribometers plotted in Fig. 3 can lead to two different conclusions. Simply considering all data, the figure indicates that tribometer wear coefficients are independent on initial contact pressure. This is an unexpected observation since highly loaded contacts are expected to wear more. Only one tribometer [74] allowed achieving the low wear coefficients obtained in simulators. This one has a particular concave/convex geometry and multi-directional motion while the other tribometers use ball on flat or flat on flat contacts and uni-directional sliding. It is not clear whenever the low wear coefficients are a result of loading, motion type or a combination of both. Another conclusion can be drawn when considering the fact that the lowest pressures plotted in Fig. 3 were obtained through nominal flat on flat configurations. However, in absence of perfect alignment between the two surfaces, a hardly achievable condition in practice, the contact of flat surfaces can become non conformal thus yielding much larger contact pressures than

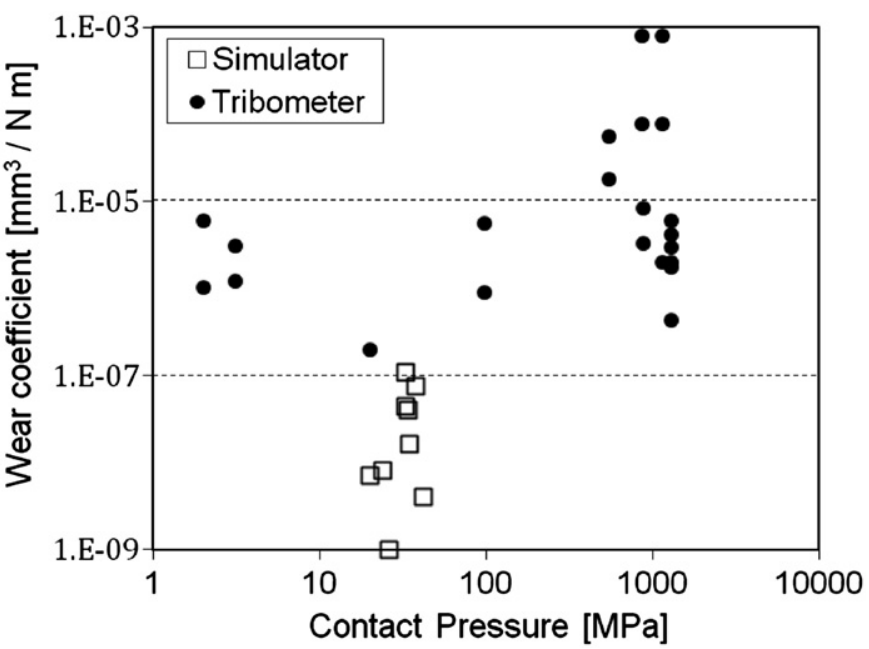

Fig. 3. The wear coefficients of the data from Tables 2 and 3 are plotted as a function of the average Hertzian contact pressure. Different symbols are used depending on experimental set-up.

the ratio between the applied load and the nominal contact area. The published papers (Table 3 ) do not describe alignment procedures or mention the quality of alignment. It is therefore difficult to draw conclusions on the real pressure established in the flat on flat tribometer contacts considered in Fig. 3. Neglecting those results, Fig. 3 leads to the conclusion that the wear coefficient increases with contact pressure independently on whether the results were obtained on a simulator or on a tribometer. Measuring tribometer wear coefficients at different well defined contact pressures down to the simulator level could confirm this hypothesis.

As a matter of fact tribometers yield more severe wear coefficients than simulators. Several reasons may explain this. First, pressures exceeding the elastic limit of the CoCrMo alloy (517 to $827 \mathrm{MPa}$ according to ISO 5832-12) yield generalized plastic deformation and therefore the risk of low cycle contact fatigue and severe wear. On the other hand low contact pressures favour hydrodynamic lubrication. Dowson [81] calculated the minimal fluid film thickness established in simulator contact using the Hamrock-Dowson relationship for elasto-hydrodynamics [80] given in Eq. (5).

$h_{\mathrm{m}}=2.80\left(U h / E^{\prime} R^{\prime}\right)^{0.65}\left(F_{\mathrm{n}} / E^{\prime} R^{\prime 2}\right)^{-0.21} R^{\prime}$

where $U$ is the velocity, $F_{\mathrm{n}}$ the applied normal force, $\eta$ the dynamic viscosity. $E^{\prime}$ is the effective elastic modulus and is defined as $2 / E^{\prime}=\left(1-v_{1}\right) / E_{1}+\left(1-v_{2}\right) / E_{2}$ where $v$ and $E$ are the Poisson ratio and the elastic moduli of the two antagonists 1 and $2 . R^{\prime}$ is the reduced radius of curvature according to $1 / R^{\prime}=1 / r_{1}+1 / r_{2}$ where $r_{1}$ and $r_{2}$ are the radius of curvature of the two antagonist in the liquid entrainment direction. By comparing steady state wear rates from independent simulator experiments and corresponding calculated elastohydrodynamic film thicknesses Dowson [81] concluded that very low wear rates (corresponding to wear coefficients in the range of $10^{-9} \mathrm{~mm}^{3} / \mathrm{N} \mathrm{m}$ ) are achieved when the film thickness exceeds $15-$ $20 \mathrm{~nm}$. Below this threshold the wear rate increases rapidly (2 orders of magnitudes when decreasing film thickness form 15 to $5 \mathrm{~nm}$ ). Eq. (5) can be applied to metal on metal bearings [81] as well as to ball on plate contacts [82]. In the latter case $R^{\prime}$ corresponds to the ball radius. In order to compare fluid film lubrication in simulators and in tribometers, Eq. (5) was applied to the present data set (Table 3) to determine the theoretical minimum film thickness $h_{\mathrm{m}}$ established in the ball on flat tribometer contacts. 
Eq. (5) yields for most of the tribometers fluid films with minimum thicknesses ranging form 0.2 to $0.4 \mathrm{~nm}$, i.e., values corresponding to one or two monolayers of water. Considering typical $R_{\mathrm{a}}$ roughness values of $10 \mathrm{~nm}$, such thin films cannot provide efficient load carrying properties as thicker hydrodynamic films found on simulators. Therefore tribometer contacts with ball on flat configuration are expected to operate mainly under boundary lubrication only and thus to suffer of wear. In simulators, which run depending on gait phase under mixed or elasto-hydrodynamic lubrication [80,81], only asperities not separated by the hydrodynamic film experience boundary lubricated wear as in the case of tribometer contacts and therefore material loss is smaller.

These explanations need of course to be substantiated by dedicated experiments performed under well-controlled loading and lubrication conditions and by the development of an appropriate formalism describing wear and lubrication in the mixed lubrication regime. This could have a significant impact in the study of tribocorrosion of CoCrMo alloys, as it would allow extrapolating tribometers results obtained under well-defined conditions to more realistic simulators and eventually to in-vivo conditions.

\subsection{Effect of potential on wear}

Electrochemical conditions are known to critically affect the tribocorrosion behaviour of metals [83]. The prevailing electrode potential (i.e., the difference in electric potential between the metal and the surrounding solution) can trigger different tribocorrosion mechanisms. The passivity of metals, which is achieved within a well defined potential domain only, may decisively affect the surface mechanical behaviour of the underlying metal and promote severe wear accelerated corrosion. At sufficiently low potentials, reduction of water or hydronium ions may cause hydrogen embrittlement in metals such as titanium or high strength steels.

Several studies conducted using tribometers working either under constant applied potential (potentiostatic tests [26]) or at open circuit potential (OCP tests [26]) with simultaneous recording of its value are available. Simulators were never run under controlled electrochemical conditions with the exception of Yan [49] who measured the evolution of the potential of a CoCrMo implant during a simulator test at open circuit. The wear coefficients collected through these works were plotted in Fig. 4 as a

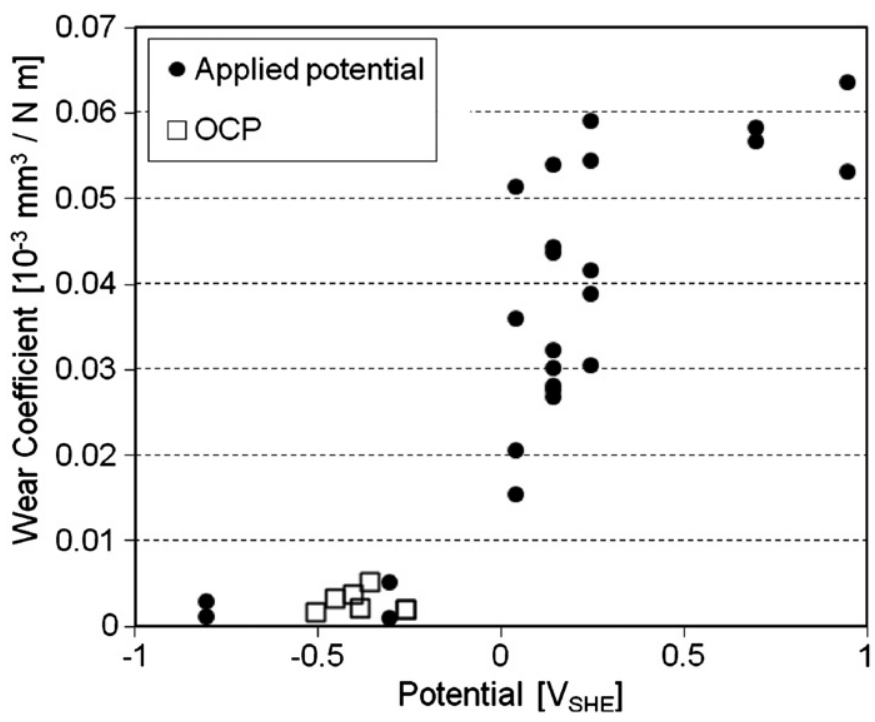

Fig. 4. Plot of the wear coefficients as a function of the CoCrMo electrode potential established in the contact. function of the applied potential or the average OCP measured during sliding at open circuit.

This figure clearly shows that the potential plays a crucial role on wear and this independently on the way the potential is established (open circuit or potentiostatic tests). Three domains can be identified in Fig. 4. For electrode potentials below approximately $-0.2 V_{\mathrm{SHE}}$ (standard hydrogen electrode) low wear coefficients $\left(10^{-6}\right.$ to $\left.5 \times 10^{-6} \mathrm{~mm}^{3} / \mathrm{N} \mathrm{m}\right)$ are observed. At potentials above approximately $0.3 \mathrm{~V}$ the wear coefficients are one order of magnitude larger (approximately $5 \times 10^{-5} \mathrm{~mm}^{3} / \mathrm{N} \mathrm{m}$ ). At intermediate electrode potentials (between -0.2 and $0.3 \mathrm{~V}$ ) the transition between low wear and high wear is characterised by significant scattering determined by the nature of the solution $[19,20,22]$, the type of alloy [20] and its heat treatment [19].

The low wear to high wear transition potential visible in Fig. 4 (0-0.3 V corresponds well with the threshold potential of $0.15 \mathrm{~V}$ [84] at which passive film thickening accelerates significantly. Recently, Espallargas et al. [85] investigated the corrosion and tribocorrosion behaviour of a pulse plasma nitrided biomedical CoCrMo alloy. They observed that CoCrMo samples containing nitrogen in solid solution exhibit neither a passive behaviour nor a potential dependent transition to high wear. These observations indicate that the potential dependent wear transition is related to the passive state of the metal. The wear promoting effect of passive films can be ascribed to two factors: first passive films are known to render metal surfaces more prone to mechanical wear $[38,86]$. Second, passive metals are subjected to wear accelerated corrosion due to the continuous cyclic removal and regrowth of the oxide film. This effect is expected to be more pronounced in case of thicker films. Passive film formation occurs only at sufficient high potentials (i.e., above the passivation potential) by reaction of the metal with water without implication of other species. This can explain the insensitivity of wear rates at the extremes of Fig. 4 to the specific nature of the electrolyte.

The strong dependence of wear on electrochemical conditions is of relevance for the implant practice as implant degradation rate may change up to one order of magnitude depending on electrode potential. The control of the electrochemical conditions in which implants operate is therefore essential and as relevant as mechanical loading.

\subsection{Electrode potential of CoCrMo contacts}

The open circuit potential of a metallic implant depends on the kinetics of the prevailing reduction and oxidation electrochemical reactions taking place on the metal surface. These in turn depend on a variety of experimental parameters including material's composition and structure, strain state, temperature, chemical composition of the environment, mass transport conditions, contact with other materials, ...For these reasons, it is very difficult to predict open circuit potentials and although its measurement is relatively easy for in-vitro tests, there is only one reported in-vivo value by Steinmann [87] of $0.2 V_{\mathrm{SHE}}$. The open circuit potentials measured in vitro $[68,75,88,89]$, in a variety of environments (bovine serum, sodium chloride and phosphate solution with and without proteins) are in the range $-0.5 V_{\text {SHE }}$ to $0.2 V_{\mathrm{SHE}}$, i.e., close to or within the transition potential range in Fig. 4. However, the in-vivo measured value [87] of $0.2 \mathrm{~V}$ is a value lying in the transition upper zone.

The electrode potential of an implant may change during time as a consequence of changes in environment and depending on mass transport, among other factors. For example, in case of inflammation, the $\mathrm{pH}$ may become more acidic and this can modify the electrode potential of the implant [90]. In case of insufficient mass transport, local accumulation of metallic ions released by corrosion can also alter the $\mathrm{pH}$ of the environment 
surrounding the implant and influence its chloride concentration [91]. In addition, hydrodynamic conditions (e.g., blood flow) around the implant surface influence mass transport limited electrochemical reactions.

Rubbing is another key factor affecting the electrode potential. Indeed, authors testing tribocorrosion of CoCrMo alloys in simulated body fluids $[22,68,75,88]$ found that the onset of rubbing corresponds to a significant (typically between 0.10 and $0.35 \mathrm{~V}$ depending on solution and load) cathodic shift of overall electrode potential. Fig. 5 shows the typical evolution of the electrode potential of a CoCrMo alloy during a tribocorrosion tests.

This effect is usually attributed to the removal of surface films by abrasion leading to an enhanced anodic reactivity of the metal exposed to the solution and thus to a modification of the electrode potential. Thus rubbing at open circuit potential can have two major electrochemical effects.

First, due to the change in potential the corrosion rate outside the wear track may significantly change. For example Igual Muñoz et al. [89] compared corrosion rates measured at the corrosion potential by different groups on CoCrMo alloys in PBS solutions. Despite the large data scattering a trend of decreasing corrosion rate with increasing potential could be observed (approximately a factor of two every $100 \mathrm{mV}$ ). Thus, rubbing is expected to enhance the corrosion rate of the hip joint metal surrounding the contact area. Considering the large area of hip joints unaffected by sliding, even a small reduction in potential may results in a significant increment of the overall metal release into the body. This aspect deserves thus to be further investigated.

The second effect of rubbing is to accelerate the corrosion rate ( $i_{\mathrm{a}}$ in Eq. (2)) inside the wear track through the abrasion of the passive film. Eq. (2) can be reformulated in order to express the extent of wear accelerated corrosion as function of geometrical and electrochemical parameters.

$E_{\text {cor }}-E_{\mathrm{c}}+a_{\mathrm{c}}-b_{\mathrm{c}} \log \left(A_{\mathrm{a}} / A_{\mathrm{c}}\right)$

The applicability of Eq. (6) to the tribocorrosion of CoCrMo alloys in simulated body fluids is subject to some limitations. The kinetics parameters $\left(E_{\mathrm{cor}}, a_{\mathrm{c}}, b_{\mathrm{c}}\right)$ can be extracted in principle from independent electrochemical measurements such as polarisation cures in the cathodic domain (i.e., for potentials below the

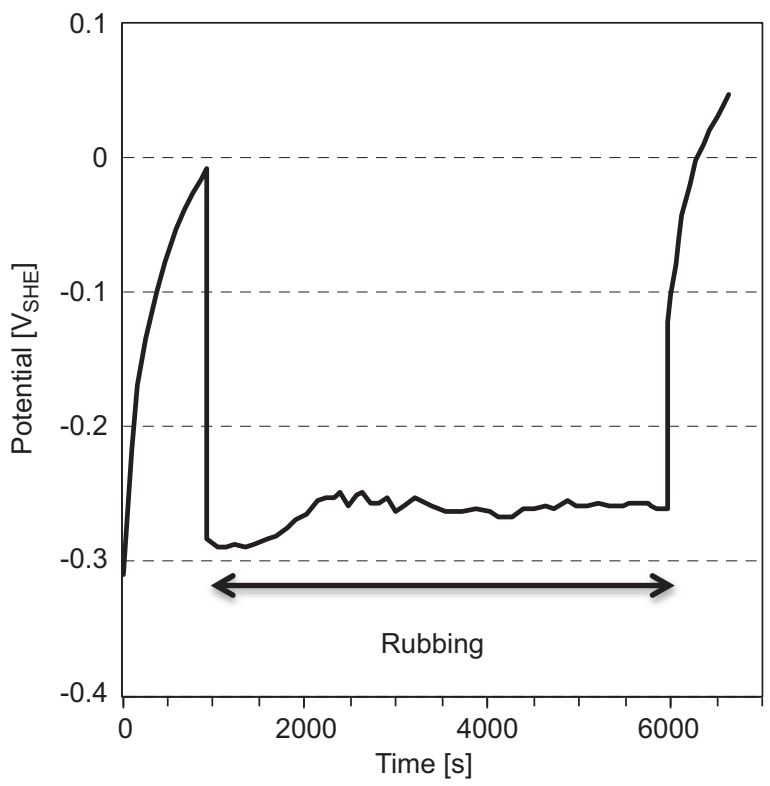

Fig. 5. Typical evolution of the electrode potential of a CoCrMo alloy during a tribocorrosion tests in simulated body fluids. Data from reference [68]. corrosion potential). Those parameters are specific for the type of alloy and solution composition. Further the experimental protocol used to measure polarisation curves is another key factor as evidenced by a recent inter laboratory investigation of the corrosion of CoCrMo alloys [89]. Here 15 laboratories from different countries applied the same protocol for measuring polarisation curves of a given CoCrMo alloy in a phosphate buffered solution with and without protein. Although repeatability within individual laboratories was good, large scattering was observed among laboratories indicating that experimental protocols as well as data extraction procedures need to be improved in order to obtain reproducible and reliable electrochemical characterisation of such alloys. The formulation of Eqs. (2) and (6) presupposes that the cathodic kinetic can be described by a Tafel behaviour (logarithmic dependence between potential and current), a situation not necessarily achieved when two or more reactions (reduction of water, oxygen or protons occur in the same potential range. Indeed, some authors [84,92,93] observed absence of Tafel behaviour while investigating corrosion of CoCrMo in simulated body fluids In these cases more complex mathematical relations between current and potential must be used.

Eq. (6) was graphically represented in Fig. 6 with $\log i_{\mathrm{a}}$ as a function of $E_{\mathrm{c}}$ for different values of the $A_{\mathrm{a}} / A_{\mathrm{c}}$ ratio. The cathodic kinetics parameters were extracted by graphical interpolation from the polarisation curve from reference Iwabuchi (Fig. 2) measured on a CoCrMo alloy in Hank's solution. Fig. 6 can be used to estimate $i_{\mathrm{a}}$ from known contact geometry ( $A_{\mathrm{a}}$ is the worn surface area, $A_{\mathrm{c}}$ the overall sample surface area) and $E_{\mathrm{c}}$ (potential measured during rubbing at open circuit). Note that these assumption are valid only when: (i) the worn area is completely depassivated, (ii) the potential is measured far from the wear track and (iii) the sample area is larger than the worn area (i.e., $\left.A_{\mathrm{a}} / A_{\mathrm{c}}<1\right)$. Unfortunately most of the published papers do not report all the parameters necessary to estimate $\mathrm{i}_{\mathrm{a}}$ : only Iwabuchi [68] reported explicitly the wear track area $\left(A_{\mathrm{a}}=5.78 \mathrm{~mm}^{2}\right)$ and the sample area exposed to the solution $\left(A_{\mathrm{c}}=200 \mathrm{~mm}^{2}\right)$ as well as the potential measured during rubbing $\left(E_{\mathrm{c}}=-0.26 V_{\mathrm{SHE}}\right)$. Considering these values, Fig. 6 yields a $i_{\mathrm{a}}$ value of $10^{-4} \mathrm{~A} / \mathrm{cm}^{2}$ (equivalent to $1 \mathrm{~mm} /$ year penetration rate) for tribocorrosion of

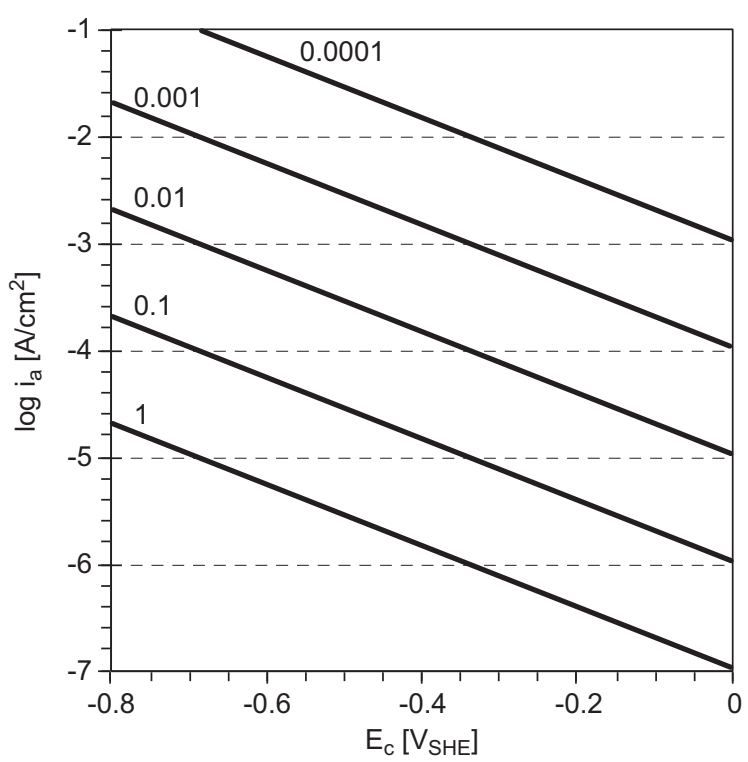

Fig. 6. Graphical representation of Eq. (6) with electrochemical parameters taken from reference [68](CoCrMo alloys, Hank's solution, $E_{\mathrm{cor}}=-0.38 V_{\mathrm{SHE}}, a_{\mathrm{c}}=$ $-2.06 \mathrm{~V}$ and $\left.b_{\mathrm{c}}=0.35\right)$. Numbers in italic indicate the $A_{\mathrm{a}} / A_{\mathrm{c}}$ ratio. 
CoCrMo alloy at OCP in Hank's solution (alumina ball as counter). This value corresponds well with the wear accelerated corrosion rate measured at applied potential as discussed in the next section.

\subsection{Wear accelerated corrosion}

During tests at applied passive potential the extent of wear accelerated corrosion can be measured by recording the current flowing through the metal/electrolyte interface an needed to sustain the imposed potential. Typically, at the onset of rubbing, the current increases due do the depassivation occurring within the wear track (Fig. 7). The excess current can be related to the material loss through Faraday's law. This interesting possibility was however exploited in only few laboratory tests. These tests involved smooth alumina [19,20] or silicon nitride balls [18] sliding over CoCrMo alloy samples kept at selected passive potentials. The tests were carried out using different loads (range 1 to $80 \mathrm{~N}$ ) and velocities ( 10 or $20 \mathrm{~mm} / \mathrm{s}$ ). In order to compare those results it is therefore necessary to use models for rationalizing the different test conditions.

As mentioned in Section 2.2 (Tribocorrosion) several models exist for describing the extent of anodic current induced by sliding on passive metals as a function of contact geometry. For the configurations used in evaluating CoCrMo alloys (metal flat sliding against polished $\mathrm{Al}_{2} \mathrm{O}_{3}$ or $\mathrm{Si}_{3} \mathrm{~N}_{4}$ balls), the most useful model is the one corresponding to a flat smooth inert counter piece sliding over a relatively rough metal. Here we consider that the hertzian elastic deformation produces a flat macroscopic contact area. Depassivation occurs thus by plastic deformation of microscopic asperities contacting the counter body within the hertzian contact area. This geometry corresponds in principle to the case $C$ in Table 1 . Under this assumption Eq. (1) can be converted into:

$I_{\mathrm{r}}=k^{*} v_{\mathrm{s}} F_{\mathrm{n}} / R_{\mathrm{Hertz}}$

With $k^{*}=k^{\prime} Q / H$. The $I_{\mathrm{r}}$ values obtained from the literature were thus plotted in Fig. 8 against the corresponding factor $v_{\mathrm{s}}$ $F_{\mathrm{n}} / R_{\text {Hertz }}$. A linear correlation (with slope $k^{*}$ of approximately $0.01 \mu \mathrm{A} \mathrm{s} / \mathrm{N}$ ) is effectively observed as expected form Eq. (7). This implies also that the physical model taken here is a good approximation of the real contact conditions. In addition this also suggest that $H$ and $Q$ do not changes considerably depending on the specific combination of CoCrMo alloy and solution. Interestingly, the nature of the solution seems to little influence wear

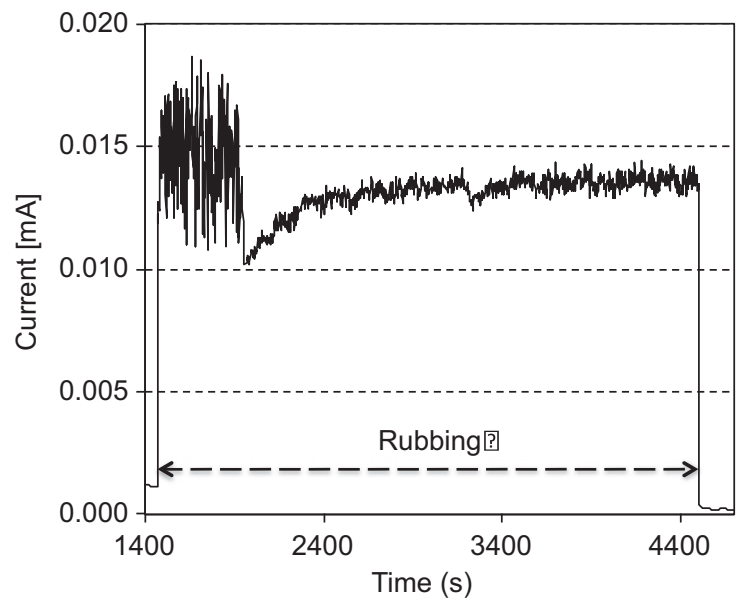

Fig. 7. Example of evolution of current for a CoCrMo alloy during tribocorrosion at imposed passive potential in a phosphate buffered solution. Data from reference [20].

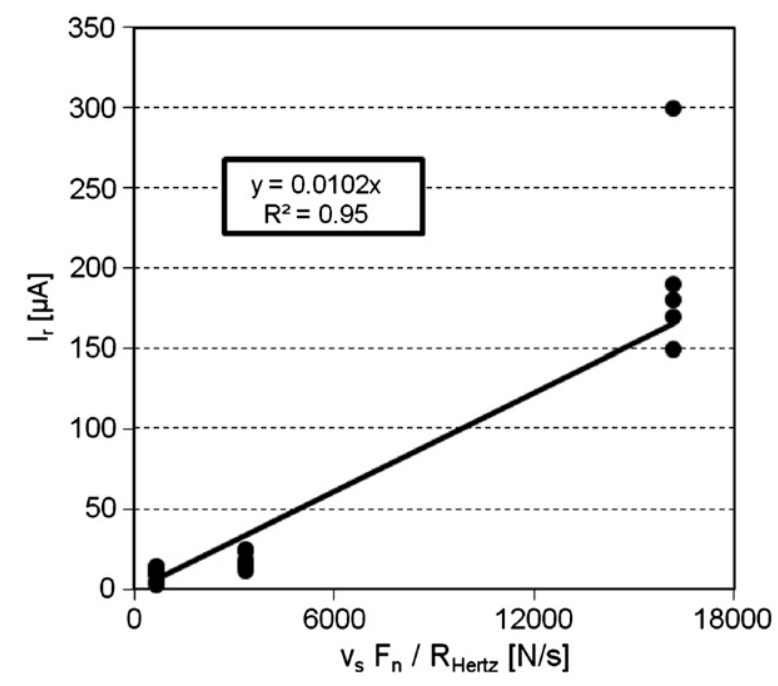

Fig. 8. Current enhancement $I_{\mathrm{r}}$ due to rubbing plotted as a function of sliding speed $v_{\mathrm{s}}$, normal load $F_{\mathrm{n}}$ and Hertzian contact radius $R_{\text {hertz }}$. Eq. (7) predicts a linear relationship. Data from references [18-20].

accelerated corrosion. Indeed, the data plotted in Fig. 8 were obtained in different solution ranging from simple $\mathrm{NaCl}$ with or without addition of proteins to calf serum and DMEM solutions. This is not surprising since passivation implies the reaction of water with the metal without direct involvement of other species.

For the practice it is usually better to convert current into linear corrosion rate $V_{\mathrm{r}}$, representing the average depth of material removed by corrosion by unit time, using Eq. (7).

$V_{\mathrm{r}}=M I_{\mathrm{r}} / n F \rho A_{\mathrm{a}}$

where $F$ is the Faraday constant ( 96500 C/equivalent), $M$ is the molecular weight of the alloy (58.6 g/mole [19]), $\rho$ and $n$ its density $\left(7.44 \mathrm{~g} / \mathrm{cm}^{3}[19]\right)$ and oxidation valence $(2.36$ equivalent per mole [84]), respectively. By combining Eqs. (7) and (8) one obtains:

$V_{\mathrm{r}}=k M v_{\mathrm{s}} F_{\mathrm{n}} / n F \rho A_{\mathrm{a}} R_{\mathrm{Hertz}}$

Eq. (9) can be applied to hip joint contacts assuming that depassivation occurs in the hertzian contact area. Thus, $A_{a}$ corresponds in principle to the hertzian contact area. Taking from Table 2 a typical load of $2000 \mathrm{~N}$ and a typical contact pressure of $30 \mathrm{MPa}$ we obtain for $A_{\mathrm{a}}=65 \mathrm{~mm}^{2}$ and $R_{\text {Hertz }}=4.55 \mathrm{~mm}$. The average sliding velocity is typically $15 \mathrm{~mm} / \mathrm{s}$. Considering $k^{*}=0.01 \mu \mathrm{A} / \mathrm{mm}^{2}$ (slope of the curve in Fig. 8) one obtains $I_{\mathrm{r}}=65 \mu \mathrm{A}$ and $V_{\mathrm{r}}=1 \mathrm{~mm} /$ year through Eqs. (7) and (9), respectively. This corrosion rate $V_{\mathrm{r}}$ is much larger than the typical corrosion rates found under static conditions for CoCrMo alloys in simulated body fluids which is approximately $0.03 \mathrm{~mm} /$ year [89]. This large difference is not surprising considering that CoCrMo alloys are passive under static condition but not necessarily during sliding when passive films can be mechanically removed.

The above described wear accelerated corrosion approach can now be compared to simulators results. Run-in wear rates measured in simulators ranges typically between 10 and $50 \mu \mathrm{m} /$ Mcycles [2]. Considering a typical cycle frequency of $1 \mathrm{~Hz}$ the wear accelerated corrosion rate of $1 \mathrm{~mm} /$ year corresponds in a hip joint simulator to a material loss rate of $30 \mu \mathrm{m} /$ Mcycle, a value fitting well the wear rates obtained in simulators. In Fig. 9 the wear coefficients measured on simulators were plotted against the reciprocal value of the hertzian contact radius. According to the above developed wear accelerated corrosion model wear should increase linearly with this value. Such a trend can be indeed observed in Fig. 9 when neglecting one outlier. 


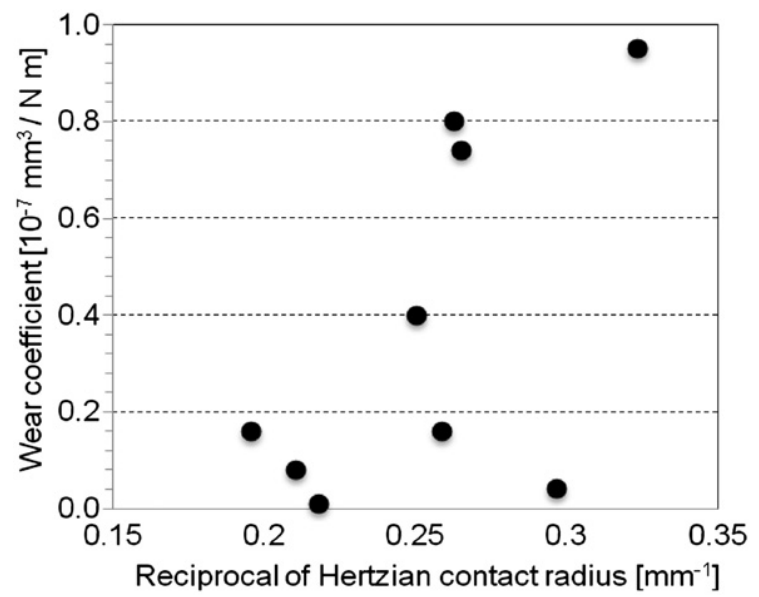

Fig. 9. Plot of the wear coefficient measured in simulators (Table 2) as a function of the reciprocal of the Hertzian contact radius.

These observations suggest that wear accelerated corrosion could constitute a major contribution to the overall degradation of CoCrMo alloys used in artificial joints. This conclusion needs to be confirmed by direct measurement of corrosion for example through simulators tests carried out under imposed electrode potential with simultaneous measurement of the corrosion current.

However, an exact prediction of the wear accelerated corrosion rate using Eq. (9) requires the knowledge of a number of factors that are still ill defined in artificial joints. For example, hydrodynamic lubrication and protein boundary lubricants can reduce the effective load $F_{\mathrm{n}}$ transmitted through asperity contacts and thus the probability $k^{\prime}$ that an asperity becomes effectively depassivated. Work hardening and tribological induced metallurgical surface transformations may significantly, depending on load conditions, change the hardness $H$ and the deformation behaviour of the asperities. Temperature changes due to friction heating and accumulation of metal ions in the solution confined within the contact may affect the electrochemical conditions and thus the passivation charge density $Q$. All these factors are at present little or not at all understood. Despite these uncertainties Eq. (9) constitutes a useful tool in order to appraise the mechanism by which different parameters interact and affect wear. For example, increasing clearance reduces the contact area $A_{\mathrm{a}}$ and the contact area radius $R_{\text {Hertz }}$ : according to Eq. (9) this results in an increase of wear accelerated corrosion and thus of wear, an effect indeed observed in practice [2]. As another example, non passive alloys (passivation charge $q=0$ ) should perform better under tribocorrosion conditions, as evidenced by the improved tribocorrosion behaviour of nitrided CoCrMo alloys reported by Bazzoni et al. [85].

\section{Conclusions}

This work was initiated with the aim to appraise the merits and limitations of existing tribocorrosion models and concepts for the description of degradation of CoCrMo metal on metal hip joints. The work is based on a review of existing literature reporting quantitative data obtained through simulator or tribometer studies on CoCrMo degradation in sliding water lubricated contacts. Electrochemical measurements necessary to appraise the role of corrosion in the overall wear process were widely used in tribometers but not, with only one exception, in simulators, which better reproduce the in-vivo mechanical situation. Electrochemical parameters had therefore to be extrapolated from tribometer to simulators using tribocorrosion models. The material degradation mechanisms considered are the following: corrosion outside the contact area, mechanical wear and wear accelerated corrosion inside the contact area [85]. For the latter predictive models based on idealized two body contact conditions exist [94].

Despite the diversity of experimental conditions and protocols used in literature some trends could be identified. In particular this study leads to the following conclusions and remarks:

- Degradation of CoCrMo in water lubricated contacts is critically affected by the prevailing electrochemical conditions. The literature data show a wear transition of more than one order of magnitude occurring above a critical potential range. This transition is attributed to the presence of a passive film although the exact mechanisms could not be identified. Despite this, it clearly appears that improved test protocols should mandatorily include the control of the electrochemical conditions during tribotesting of CoCrMo in simulated body fluids.

- Corrosion of the CoCrMo implant areas surrounding the contact zone is expected to increase significantly during rubbing. This effect is due to the galvanic coupling established during rubbing between the worn area (enhanced anodic oxidation of the metal following mechanical depassivation) and the surrounding passive metal. As a consequence, the electrode potential of the passive CoCrMo alloy decreases as confirmed by the experimental evidence obtained in simulators as well as using tribometers, where potential drops up to several hundreds of millivolts were reported. According to the existing knowledge available on corrosion of CoCrMo alloys such a potential decrease should significantly increase the corrosion rate and thus contribute to the overall material release from implants. However, precise measurements of the corrosion rate in the potential region below the typical corrosion potentials established in absence of rubbing are needed in order to assess the effective impact of motion on the corrosion rate of implants.

- Wear accelerated corrosion due to depassivation of worn areas is likely to contribute significantly to the overall contact degradation. Its contribution was evaluated using two models: the galvanic coupling formalism proposed by Vieira et al. [35] and the two body abrasion mechanism proposed by Landolt et al. [31]. Based on fitting of the limited electrochemical data obtained for wear tests at open circuit potential or at applied passive potential, both methods yield consistent values of wear accelerated corrosion of approximately $1 \mathrm{~mm} /$ year $\left(0.1 \mathrm{~mA} / \mathrm{cm}^{2}\right)$. For simulators operating at $1 \mathrm{~Hz}$ motion frequency this value corresponds to a wear rate of $30 \mu \mathrm{m} / 10^{6}$ cycles, a value in the same order of magnitude than the wear of CoCrMo hip joints measured on simulators. This indicates that wear accelerated corrosion constitutes a major contribution to the overall degradation of metallic implants.

- Despite the simple premises on which they are based, present mechanistic tribocorrosion models have shown to be useful tools to appraise chemical aspects of CoCrMo degradation. Their applicability and limits should be further evaluated using an extended set of data collected through dedicated tribological experiments using well defined experimental protocols. Further, a better understanding of the passivation of CoCrMo alloys needs to be established over a wide range of anodic and cathodic potentials representative of the in-vivo tribocorrosion situations.

\section{Acknowledgments}

A. Igual Muñoz expresses her gratitude to the Ministerio de Ciencia e Innovación of the Spanish government for the financial support under the project MAT2011-22481. 


\section{References}

[1] S.B. Goodman, E.ómez Barrena, M. Takagi, Y.T. Konttinen, Journal of Biomedial Materials Research (2008) 603-618.

[2] C.B. Rieker, R. Schön, P. Köttig., The Journal of Arthroplasty 19 (8) (2004) 5-11.

[3] A. Grübl, M. Marker, W. Brodner, A. Giurea, G. Henze, V. Meisinger, et al., Journal of Orthopaedic Research (2007) 841-848.

[4] A. Sargeant, T. Goswami, Materials \& Design 28 (2007) 155-171.

[5] I. Milosev, M. Remskar, In vivo production of nanosized metal wear debris formed by tribochemical reaction as confirmed by high-resolution TEM and XPS analysis, Journal of Biomedical Materials Research Part A 91(A) (2008) $1100-1110$.

[6] A.J. Hart, P.D. Quinn, B. Sampson, A. Sandisson, K.D. Atkinson, J.A. Skinner, et al., Acta Biomaterialia 6 (2010) 4439-4446.

[7] P.M. Whittingham-Jones, E. Dunstan, H. Altaf, S.R. Cannon, P.A. Revell, W.R. Briggs, The Journal of Arthroplasty 23 (8) (2008) 1212-1218.

[8] M. Huber, G. Reinisch, G. Trettenhahn, K. Zweymüller, F. Lintner, Acta Biomaterialia 5 (2009) 172-180.

[9] G. Reinisch, K.P. Judmann, C. Lhotka, F. Lintner, K.A. Zwymüller, Biomaterials 24 (2003) 1081-1091.

[10] R. Büscher, A. Fischer, Wear 259 (2005) 887-897.

[11] A.W. Hodgson, S. Mischler, B. Von Rechenberg, S. Virtanen, Journal of Engineering in Medicine: Part H 221 (2007) 291-303.

[12] R. Büscher, G. Täger, W. Dudzinski, B. Gleising, M.A. Wimmer, A. Fischer, Journal of Biomedial Materials Research 72B (1) (2004) 206-214.

[13] M.A. Wimmer, A. Fischer, R. Büscher, R. Pourzal, C. Sprecher, R. Hauert, et al. Journal of Orthopeadic Research (2009) 1-8.

[14] M.A. Wimmer, C. Sprecher, R. Hauert, G. Täger, A. Fischer., Wear 255 (2003) 1007-1014.

[15] J.H. Dumbleton, M.T. Manley, The Journal of Arthroplasty 20 (2) (2005) $174-188$.

[16] L. Mattei, F. Di Puccio, B. Piccigallo, E. Ciulli, Tribology International 44 (5) (2011) 532-549.

[17] S. Affatato, M. Spinelli, M. Zavalloni, C. Mazzega-Fabbro, M. Viceconti, Medical Engineering \& Physics 30 (10) (2008) 1305-1317.

[18] Y. Yan, A. Neville, D. Dowson, Wear 263(7-12) (2007) 1105-1111.

[19] L. Casaban Julian, A. Igual Muñoz, Tribology International 44 (3) (2011) 318-329.

[20] A. Igual Muñoz, S. Mischler, Journal of Materials Science: Materials in Medicine 22 (2011) 437-450

[21] M.T. Mathew, P. Srinivasa Pai, R. Pourzal, A. Fischer, M.A. Wimmer, Advances in Tribology 2009 (2009) 1-12.

[22] Stähli C., Stojadinovic J., Mischler S. Tribocorrosion assessment of biomedical alloys: Influence of chemical and electrochemical parameters. December 2-4 2, (Ed.). 2010. Ranchi, India, Seventh International Conference on Industrial Tribology, ICIT-2010.

[23] A. Neville, Y. Yan, Biotribocorrosion: surface interactions in total joint replacement (TJR), in: D. Landolt, S. Mischler (Eds.), Tribocorrosion of Passive Metals and Coatings, Woodhead Publishing, Lausanne, 2011.

[24] M.T. Mathew, T. Uth, N.J. Hallab, R. Pourzal, A. Fischer, M.A. Wimmer, Wear 271(9-10) (2011) 2651-2659.

[25] M.T. Mathew, M.A. Wimmer, Tribocorrosion of Passive Metals and Coatings, Woodhead Publishing, Lausanne, 2011.

[26] S. Mischler, Tribology International 41 (7) (2008) 573-583.

[27] M. Kedam, F. Wenger, Electrochemical methods in tribocorrosion, in: D. Landolt, S. Mischler (Eds.), Tribocorrosion of Passive Metals and Coatings, Woodhead Publishing, Cambridge, 2011, pp. 187-218.

[28] M. Azzi, J.E. Klemberg-Sapieha, Tribocorrosion test protocols for sliding contacts, in: D. Landolt, S. Mischler (Eds.), Tribocorrosion of Passive Metals and Coatings, Woodhead Publishing, Cambridge, 2011, pp. 222-237.

[29] H.H. Uhlig, Mechanism of fretting corrosion, Journal of Applied Mechanics (1954) 401-407.

[30] S. Mischler, S. Debaud, D. Landolt, Journal of Electrochemical Society 145 (3) (1998) $750-758$.

[31] D. Landolt, S. Mischler, M. Stemp, Electrochimica Acta 46(24-25) (2001) 3913-3929.

[32] C.B. der Ohe, R. Johnsen, N. Espallargas, Wear 269(7ГÇô8) (2010) 607-616.

[33] A. Igual Muñoz, N. Espallargas, Tribocorrosion mechanisms in sliding contacts, in: D. Landolt, S. Mischler (Eds.), Tribocorrosion of Passive Metals and Coatings, Woodhead Publishing, Lausanne, 2011

[34] R. Roscoe, Philosophical Magazine 21 (1926) 399-406.

[35] A.C. Vieira, L.A. Rocha, N. Papageorgiou, S. Mischler, Corrosion Science 54 (0) (2012) 26-35

[36] J. Stojadinovic, D. Bouvet, M. Declercq, S. Mischler, Tribology International 42 (4) (2009) 575-583.

[37] N. Espallargas, S. Mischler., Tribology International 43 (7) (2010) 1209-1217.

[38] M. Favero, P. Stadelmann, S. Mischler, Journal of Physics D: Applied Physics 39 (2006) 3175-3183.

[39] J. Perret, E. Boehm-Courjault, M. Cantoni, S. Mischler, A. Beaudouin, W. Chitty, et al., Wear 269(5-6) (2010) 383-393.

[40] Y. Sun, E. Haruman, Surface and Coatings Technology 205(17-18) (2011) $4280-4290$

[41] J. Stojadinovic, L. Mendia, D. Bouvet, M. Declercq, S. Mischler, Wear 267(1-4) (2009) 186-194.
[42] A. Bidiville, M. Favero, P. Stadelmann, S. Mischler, Wear 263(1-6) (2007) 207-217.

[43] J. Jiang, M.M. Stack, Wear 261 (9) (2006) 954-965.

[44] J.P. Paul, Proceedings of the Institution of Mechanical Engineers 181 (3J) (1967) 8-15.

[45] R.C. Johnston, G.L. Smidt, The Journal of Bone and Joint Surgery 51A (6) (1969) 1083-1094.

[46] J.P. Kretzer, M. Krachler, J. Reinders, E. Jakubowitz, M. Thomsen, C. Heisel, Determination of low wear rates in metal-on-metal hip joint replacements based on ultra trace element analysis in simulator studies, Tribology Letters 37 (2010) 23-29.

[47] IJ. Leslie, S. Williams, C. Brown, J. Anderson, G. Isaac, P. Hatto, Surface engineering: a low wearing solution for metal-on-metal hip surface replacements, Journal of Biomedical Materials Research Part B: Applied Biomaterials 90 (2009) 558-565.

[48] J.G. Bowsher, I.C. Clarke, P.A. Williams, T.K. Donaldson, What is a normal wear pattern for metal-on-metal hip bearings? Journal of Biomedical Materials Research Part B: Applied Biomaterials 91B (2009) 297-308.

[49] Y. Yan, A. Neville, D. Dowson, S. Williams, J. Fisher, Wear 267(5-8) (2009) 683-688.

[50] A. Unsworth, Tribology of artificial hip joints, Proceedings of the Institution of Mechanical Engineers, Part J: Journal of Engineering in Medicine 220 (2006) 711-718.

[51] C. Brockett, S. Williams, Z. Jin, G. Isaac, J. Fischer, Friction of total hip replacements with different bearings and loading conditions, Journal of Biomedical Materials Research Part B: Applied Biomaterials 81B (2006) 508-515.

[52] C.B. Rieker, R. Schon, R. Konrad, G. Liebentritt, P. Gnepf, M. Shen, Influence of the clearance on in-vitro tribology of large diameter metal-on-metal articulations pertaining to resurfacing hip implants, Orthopaedic Clinics of North America 36 (2005) 135-142.

[53] J. Fisher, X.Q. Hu, T.D. Stewart, S. Williams, J.L. Tipper, E. Ingham, Wear of surface engineered metal-on-metal hip prostheses, Journal of Materials Science: Materials in Medicine 15 (2004) 225-235.

[54] I. Catelas, J.B. Medley, P.A. Campbell, O.L. Huk, J.D. Bobyn, Journal of Biomedical Materials Research Part B: Applied Biomaterials 70B (2) (2004) 167-178.

[55] K.R.St John, L.D. Zardiackas, R.A. Poggie, Journal of Biomedial Materials Research 68B (1) (2003) 1-14.

[56] I. Catelas, J.D. Bobyn, J.B. Medley, J.J. Krygier, D.J. Zukor, O.L. Huk, Journal of Biomedial Materials Research 67A (1) (2003) 312-327.

[57] P.J. Firkins, J.L. Tipper, E. Ingham, M.H. Stone, R. Farrar, J. Fisher, Journal of Biomechanics 34 (10) (2001) 1291-1298.

[58] S.C. Scholes, A. Unsworth, R.M. Hall, R. Scott, Wear 241 (2) (2000) 209-213.

[59] G.W. Stachowiak, A.W. Batchelor, Engineering Tribology, Elsevier Butterwoth-Heinemann, Burlington, 2005.

[60] K.K. Wang, A. Wang, L.J. Gustavson, Metal-on-metal wear testing of $\mathrm{CoCr}$ alloys. Cobalt-base alloys for biomedical applications ASTM STP 1365, ASTM (1999) 135.

[61] Y. Yan, A. Neville, D. Dowson, S. Williams, Tribology International 39 (12) (2006) 1509-1517.

[62] Q. Bi, W. Liu, J. Ma, J. Yang, Y. Pu, Q. Xue, Tribology International 42 (7) (2009) 1081-1087.

[63] F. Contu, B. Elsener, H. Böhni, Corrosion Science 47 (8) (2005) 1863-1875.

[64] C.B. Santos, L. Haubold, H. Holeczek, M. Becker, M. Metzner, Wear-corrosion resistance of DLC/CoCrMo system for medical implants with different surface finishing, Tribology Letters 37 (2010) 251-259.

[65] A. Igual Muñoz, L. Casaban Julian, Electrochimica Acta 55 (19) (2010) 5428-5439.

[66] H. Mishina, M. Kojima, Wear 265 (2008) 655-663.

[67] A. Chiba, K. Kumagai, N. Nomura, S. Miyakawa, Acta Materialia 55 (4) (2007) 1309-1318.

[68] A. Iwabuchi, J.W. Lee, M. Uchidate, Wear 263(1-6) (2007) 492-500.

[69] A. Mitchell, P. Shrotriya, Wear 263(7-12) (2007) 1117-1123.

[70] R. Varano, J.D. Bobyn, J.B. Medley, S. Yue, The effect of microstructure on the wear of cobalt-based alloys used in metal-on-metal hip implants, Proceedings of the Institution of Mechanical Engineers, Part $\mathrm{H}$ : Journal of Engineering in Medicine 220 (2006) 145-159.

[71] S. Spriano, E. Vernè, M.G. Faga, S. Bugliosi, G. Maina, Wear 259 (2005) 919-925.

[72] R. Büscher, A. Fischer, Metallurgical aspects of sliding wear of fcc materials for medical applications, Mat.-Wiss.u.Werkstofftech 34 (2003) 966-975.

[73] S.C. Scholes, A. Unsworth., Journal of Materials Science: Materials in Medicine 12 (2001) 299-303.

[74] M.A. Wimmer, J. Loos, R. Nassutt, M. Heitkemper, A. Fischer, Wear 250(1-12) (2001) 129-139.

[75] Y. Yan, A. Neville, D. Dowson, Journal of Physics D: Applied Physics 39 (2006) 3200-3205.

[76] Y. Yan, A. Neville, D. Dowson, Understanding the role of corrosion in the degradation of metal-on-metal implants, 220[Proceedings of the Institution of Mechanical Engineers, Part H: Journal of Engineering in Medicine] (2006) 173-181.

[77] Y. Yan, A. Neville, D. Dowson, Tribology International 40 (2007) 1492-1499.

[78] H.W. Fang, M.C. Hsieh, H.T. Huang, C.Y. Tsai, M.H. Chang, Colloids and Surfaces B: Biointerfaces 68 (2) (2009) 171-177. 
[79] R. Crockett, M. Roba, M. Naka, B. Gasser, D. Delfosse, V. Frauchiger, et al., Friction, lubrication, and polymer transfer between UHMWPE and CoCrMo hip-implant materials: a fluorescence microscopy study, Journal of Biomedical Materials Research Part A (2008).

[80] B. Hamrock, D. Dowson, Journal of Lubrication Technology-Transactions on ASME 100 (1978) 236-245.

[81] D. Dowson, The Relationship Between Steady-State Wear Rate and Theoretical Film Thickness in Metal-on-Metal Total Replacement Hip Joints in Tribological Research and Design for Engineering Systems, Proceedings of the 29th Leeds-Lyon Symposium on Tribology, Elsevier, 2003, p. 273.

[82] C. Myant, T. Reddyhoff, H.A. Spikes, Tribology International 43 (11) (2010) 1960-1969.

[83] D. Landolt, S. Mischler, Tribocorrosion of Passive Metals and Coatings, Woodhead Publishing, Lausanne, 2011.

[84] A.W.E. Hodgson, S. Kurz, S. Virtanen, V. Fervel, C.O.A. Olsson, S. Mischler, Electrochimica Acta 49 (2004) 2167-2178.

[85] A. Bazzoni, S. Mischler, N. Espallargas, Tribology Letters (2012), http://dx.doi. org/10.1007/s11249-012-0047-0, Submitted.

[86] A. Bidiville, M. Favero, P. Stadelmann, S. Mischler, Wear 263(1-6) (2007) 207-217.
[87] S.G. Steinmann, Corrosion of surgical implants - in vivo and in vitro tests, in: G.D. Winter, J.L. Leray, K. de Groot (Eds.), Evaluation of Biomaterials, John Wiley \& Sons Ltd., 1980, pp. 1-34.

[88] R. Alonso Gil, A. Igual Muñoz, Journal of the Mechanical Behavior of Biomedical Materials 4 (8) (2011) 2090-2102.

[89] A. Igual Muñoz, S. Mischler, Inter-Laboratory Study on Electrochemical Methods for the Characterisation of CoCrMo Biomedical Alloys in Simulated Body Fluids. Wakefield, UK. Maney Publishing, 2011.

[90] C. Valero Vidal, A. Igual Muñoz, Electrochimica Acta 56 (24) (2011) 8239-8248.

[91] S. Virtanen, I. Milosev, E. Gomez-Barrena, R. Trebíe, J. Salo, Y.T. Konttinen, Acta Biomaterialia 4 (3) (2008) 468-476.

[92] A. Igual-Muñoz, S. Mischler, Jorunal of the Electrochemical Society 154 (10) (2007) C562-C570

[93] A. Kocijan, I. Milosev, B. Philar, Journal of Materials Science: Materials in Medicine 15 (2004) 643-650.

[94] D. Landolt, S. Mischler, M. Stemp, Electrochimica Acta 46 (2001) 3913-3929. 